\title{
Inequality and Financial Fragility ${ }^{*}$
}

\author{
Yuliyan Mitkov \\ Department of Economics, Rutgers University
}

March 2016

\begin{abstract}
I study how the distribution of wealth influences the government's response to a banking crisis and the fragility of the financial system. When the wealth distribution is unequal, the government's bailout policy during a systemic crisis will be shaped in part by distributional concerns. In particular, government guarantees of deposits will tend to be credible for relatively poor investors, but may not be credible for wealthier investors. As a result, wealthier investors will have a stronger incentive to panic and, in equilibrium, the institutions in which they invest are more likely to experience a run and receive a bailout. Thus, without political frictions and under a government that is both benevolent and utilitarian, bailouts will tend to benefit wealthy investors at the expense of the general public. Rising inequality can strengthen this pattern. In some cases, more progressive taxation reduces financial fragility and can even raise equilibrium welfare for all agents.
\end{abstract}

*I thank Todd Keister, Roberto Chang, Tomas Sjöström, John Landon-Lane, Eugene White and participants at seminar presentations at Rutgers and the Midwest Macro Meetings at the University of Rochester for their insightful comments and suggestions. Email: ymitkov@economics.rutgers.edu 


\section{Introduction}

In most of the theoretical literature on banking panics, both deposit insurance and panics are all-or-nothing affairs, in the sense that all deposits are treated equally and a panic affects all banks the same way. However, the financial crises observed in reality are more complicated. Deposit insurance typically covers some types of deposits (particularly smaller retail deposits), but not others. Panics are often restricted to certain types of institutions or arrangements (money market mutual funds in the United States in 2008) while others remain effectively insured by the government (commercial banks in the United States in 2008). Even within a single institution, some depositors may be forced to accept a haircut, whereas others are protected in full by the government (Cyprus in 2008). In addition, the written rules of the deposit insurance program might be abandoned in a systemic financial collapse, so that a banking crisis transforms the government guarantees from a legal to political commitment (Sibert, 2013). These issues have led some observers to question the view that government deposit insurance can solve the problem of banking panics (Cooper and Kempf, 2015) ${ }^{1}$

In this paper, I study a version of the Diamond and Dybvig (1983) model of financial intermediation where the distribution of investors' wealth influences the government's response during financial crisis, which in turn determines banks' susceptibility to financial panics. Introducing wealth inequality allows me to capture the heterogeneity across types of investors and financial intermediaries that appears to be an important factor behind the government's emergency response to a crisis. As in Keister (2015), fiscal policy is introduced via a government that collects taxes and uses the proceeds to finance the provision of a public good or to bail out banks during a panic. Importantly, the government cannot pre-commit to the details of the bailout plan before the crisis, but instead chooses the bailout policy after the crisis is already underway. I restrict attention to self-fulfilling financial panics since doing so allows me to highlight the main implications of the model in a clear and concise way.

I begin by showing that the ex-post optimal bailout policy generates endogenous caps to deposit insurance and these caps will be a decreasing function of investors' wealth levels. . $^{2}$ Thus, when wealth is unequally distributed, the bailout policy of the government will impose larger haircuts on the wealthy investors. At the same time, expecting larger losses in a financial crisis, the wealthy will be more prone to panic and run on the banks - an event which leads the government to bail them out - thus creating a self-fulfilling panic-and-bailout cycle. Importantly, the model predicts that the wealthy investors will be endogenously more likely to receive bailouts in equilibrium, even though they have no particular power or inside con-

\footnotetext{
${ }^{1}$ A case in point is the Icesave dispute, taking place after the collapse in 2008 of the Icelandic bank Landsbanki. The Court of Justice of the European Free Trade Association States (EFTA) ruled that the Icelandic government was not under the legal obligation to adhere to its original promise to insure Dutch and UK depositors, since doing so would have undermined the stability of the Icelandic banking system.

${ }^{2}$ In this paper, deposit insurance is broadly interpreted to include different forms of ex-post bailouts to banks, regardless of whether the actual transfer of public funds to the financial sector stems from an explicit or an implicit government guarantee.
} 
nections. In fact, throughout the paper, I assume that the government is both utilitarian and benevolent. An equilibrium where the wealthy investors panic and receive a bailout is possible because the government will not find it ex-post optimal to provide a rescue package that is sufficient to prevent them from panicking in the first place.

The second contribution of the paper is to shed new light on the link between widening inequality and financial fragility. One of the effects of higher inequality is to make the panicand-bailout cycle for the wealthy investors easier to obtain in equilibrium. At the same time, higher inequality makes investors with lower levels of wealth less prone to panic. This result might appear surprising at first, but the mechanism leading to this outcome within the model is relatively straightforward. A more unequal wealth distribution strengthens the utilitarian concerns of the government and therefore leads to a bailout intervention imposing relatively larger haircuts on the wealthy and lower haircuts on the poor. Thus, when inequality is sufficiently high, the utilitarian incentives of the government will prevent the poor from panicking and, at the same time, will lead to an equilibrium characterized by a panic and a subsequent bailouts for the wealthy investors.

Widening inequality could also have a negative fiscal capacity effect, since a government with limited redistributive power will respond to rising inequality by collecting less tax revenue. The reason is that keeping the same tax revenue stream would place a large burden on the increased fraction of relatively poor agents who have high marginal utility of consumption and therefore high marginal cost of paying an additional dollar in taxes. At the same time, a fall in tax revenue has a negative effect on financial stability since the government's tax revenue is related to the stability of the financial system. In particular, a government that collects less tax revenue has a lower capacity to rescue the banking sector, which in turn will make investors more prone to panic and run on the banks.

Finally, the analysis in the paper provides a novel justification for progressive taxation in times of rising inequality. In particular, if the promise of deposit insurance fails to be credible for wealthy investors, then they will be susceptible to financial panics. One way to restore credibility is to redistribute some of their wealth. This redistribution could prevent the selffulfilling panic and bailout cycle for wealthy investors and therefore be desirable, provided that the efficiency loss from the increased progressivity is not prohibitively large. In fact, wealthy investors might also be willing to accept a more progressive tax code if this is the cost of making the government's guarantees credible.

Related literature. This paper is related to the recent work of Cooper and Kempf (2015), who study the government' ex post decision to provide deposit insurance in a version of the Diamond and Dybvig model where depositors have heterogeneous wealth levels. They show that ex-post, the government will abstain from providing deposit insurance if it entails high levels of undesirable redistribution. Copper and Kempf assume that the government must either provide deposit insurance to everyone or abstain from providing deposit insurance completely. In 
contrast, I allow for more flexible bailout interventions in which the government may choose to impose different haircuts on different investors, as often occurs during a systemic crisis. In addition, I analyze a model where agents incorporate the ex-ante probability of a bank run into their decisions (as in Cooper and Ross, 1998, Peck and Shell, 2003, and others). This approach allows me to analyze bailout interventions in equilibria where runs occur with positive probability. Cooper and Kempf (2015), on the other hand, restrict their analysis to financial arrangements that do not reflect the possibility of a bank run and focus on equilibria where the ex-post intervention prevents the run from taking place in equilibrium.

One of the main contributions of the paper is to examine the link between widening inequality and financial instability. Stiglitz (2009, 2012) and Fitoussi and Saraceno (2010, 2011) posit that widening income disparity during the years preceding the 2007-08 Financial Crisis depressed aggregate demand since it redistributed income from those with high propensity to consume to those with low propensity to consume (i.e. from low to high income individuals). The monetary policy response was to prop up aggregate demand by a prolonged period of low interest rates, which in turn set the stage for a credit expansion followed by the subsequent bust. According to Rajan (2010) increased inequality unleashes political pressures for more redistribution. This redistribution could take on forms - like subsidized lending for the poor - that introduce distortions and compromise the stability of the financial system. Acemoglu (2011) argues that rising inequality does not lead to redistributive policies benefiting the low and middle income voters, but instead to policies - like financial deregulation - which tend to disproportionately benefit the wealthy. This development arises because of political frictions, whereby the government is swayed by the preferences of the minority of high income voters, instead of the preferences of the majority of low and middle income voters. Kumhof and Rancière (2011) analyze a closed economy DGSE model where increased inequality pushes households in the lower part of the income distribution to become more indebted in order to maintain their standards of living, which in turn, makes the financial system less stable.

The model in this paper does not rely on political factors to derive a link between widening inequality and financial instability. Instead, a financial crisis is a form of coordination failure between investors. Whether such a coordination failure is possible in equilibrium for a given type of investors depends crucially on the way the bailout intervention of the government will treat different type of investors in case their panic. Changes in the distribution of wealth are therefore linked to financial fragility through their effect on the government's bailout policy.

One of the key assumptions in the paper is that the bailout policy is chosen in an ex-post efficient way after the advent of the crisis. The goal of this assumption is to capture the renegotiation of government guarantees that appears to play a major role in times of systemic banking failures. Ex-post efficient bailout policy has been analyzed by, among others, Chari and Kehoe (2010), Farhi and Tirole (2012), Nosal and Ordonez (2013), Ranciere and Tornell (2011) and Bianchi (2012) and Keister (2015).

The rest of the paper is organized as follows. The model is presented in section 2. Section 3 
derives the properties of the panic equilibrium, while Section 4 analyzes the effect of increasing inequality on financial fragility. Section 5 augments the model to allow for a more general process by which investors choose where to place their deposits. Section 6 concludes. All proofs are collected in the appendix.

\section{The Model}

I extend a version of the Diamond and Dybvig model with fiscal policy and no commitment, as in Keister (2015), to include heterogeneous wealth levels among the investors.

\subsection{The environment}

Investors There are three time periods $t=0,1,2$ and a continuum of investors indexed by $i \in[0,1]$. Each investor has preferences characterized by

$$
u\left(c_{1}^{i}+\omega_{i} c_{2}^{i}\right)+v(g)=\frac{\left(c_{1}^{i}+\omega_{i} c_{2}^{i}\right)^{1-\gamma}}{1-\gamma}+\delta \frac{g^{1-\gamma}}{1-\gamma}, \quad \gamma>1 \text { and } \delta>0
$$

where $c_{t}^{i}$ is the consumption of the private good in period $t=1,2$ and $g$ is the level of the public good, which is provided in period 1 . For each investor, the parameter $\omega_{i}$ can only take values in $\{0,1\}$. If $\omega_{i}=0$, investor $i$ is impatient and values consumption only in period 1 . If $\omega_{i}=1$, investor $i$ is patient and values consumption equally in period 1 and 2 . All investors have the same probability $\pi$ of being impatient and $\pi$ is also the fraction of impatient investors in the population.

Endowments At the beginning of period 0, the only difference between investors is their initial endowment $e$. In particular, I define a function $E$ which maps each investor $i \in[0,1]$ to his endowment $e \in\left[e_{L}, e_{H}\right]$ :

$$
E:[0,1] \rightarrow\left[e_{L}, e_{H}\right]
$$

Investors with endowment $e$ will be called type e investors. The function $E$ is common knowledge and the average endowment, $\int_{e_{L}}^{e_{H}} e d G(e)$, is normalized to 1 , where $G(e)$ denotes the fraction of investors whose endowment is less or equal to $e$.

Technology Following Diamond and Dybvig (1983), there is a single, constant-return-toscale technology, operated at a central location, which takes one unit of endowment in the initial period and transforms it into 1 unit of private consumption if liquidated in period 1 . Every unit of endowment placed in the technology and not liquidated in the intermediate period yields $R>1$ units of private consumption in the final period. 
Sequential service Investors' opportunity to contact the central location in order to withdraw arrives sequentially in a randomly determined order. Ex-ante, investors are equally likely to occupy any position in the order of opportunities to withdraw. At the beginning of period 1, each investor $i$ learns whether he is patient or impatient and, in addition, his position $l(i) \in[0,1]$ in the order of opportunities to withdraw. An investor with $l=0$ knows that he is the first with an opportunity to withdraw, whereas an investor with $l=1$ knows that he will be the last with an opportunity to withdraw. Each investor's order in the opportunities to withdraw is private information. When an investor's opportunity to withdraw arrives, he can either contact the central location and receive his payment or wait until the final period to withdraw. Investors are isolated from each other and those that withdraw in period 1 must consume immediately what is given to them and return to isolation. Wallace $(1989,1990)$ shows that this environment generates a sequential service constraint where the consumption of an investor depends only on the information available to the intermediation scheme at the time he withdraws..$^{3}$

\subsection{The decentralized economy}

The constant-return-to-scale technology is operated by a continuum of banks. There is also a government who taxes investors' endowments at the beginning of period 0 and then uses the tax proceeds to provide a public good in period 1 and to make fiscal transfers (bailouts) to banks experiencing a run. Each investor chooses his withdrawing strategy as a part of a non-cooperative game between investors, the banks and the government. The possibility of financial panics is introduced via a sunspot state.

Banks Banks perform an intermediation service by pooling investors' resources in the constant-return-to-scale technology with the goal of insuring them against idiosyncratic liquidity shocks. The banks observe investors' initial endowment and their choice to withdraw in the intermediate or in the final period. However, banks dot not observe whether a given investor is patient or impatient nor his position in the order of opportunities to withdraw and, therefore, payments cannot be made contingent on this information. In addition, banks cannot commit to a future plan of action. Instead, the payment to each investor is determined as a best response to the available information at the time of the withdrawal. The assumption of nocommitment is crucial for the results to follow. In contrast, if banks could pre-commit to their payment schedules, an equilibrium bank run will be prevented by suspending payments whenever more than a fraction $\pi$ of the investors attempts to withdraw in period 1 (see Diamond and Dybvig (1983)). $4^{4}$ Finally, banks behave competitively by taking economy-wide outcomes

\footnotetext{
${ }^{3}$ This is different from the original approach of Diamond and Dybvig (1983), where after deciding to withdraw in period 1 each investor is randomly assigned a position in the withdrawing order. As shown in Green and Lin (2003), Andolfatto et. al. (2007) and Enis and Keister (2009b), investors' information about their position in this order plays an important role in the type of bank runs that can occur in equilibrium.

${ }^{4}$ Ennis and Keister (2009a), on the other hand, show how lack of commitment can undermine a strict policy of suspension of convertibility and hence fail to prevent a run on the banks from taking place in equilibrium.
} 
as independent of their actions and their objective is to maximize the expected utility of their investors at all times.

The government The government is both benevolent and utilitarian and therefore each investor is assigned the same weight in the social welfare function. The government collects taxes in period 0 by taxing investors' endowments. The tax rate $\tau$ must be the same for all investors and taxing is not possible after period 0 . In period 1 , the government allocates the tax proceeds between the provision of a public good and fiscal transfers to the financial sector (bailouts). The government is restricted to provide bailouts only to those banks experiencing a run. If $\tau$ denotes the tax proceeds and $B$ the aggregate transfers to the banking sector, then the level of public good will be equal to $\tau-B$. The government cannot commit ex-ante to the details of the rescue plan and therefore will choose the bailout payments as a best response to the prevailing conditions at the time of the intervention. 5

Financial panics Following Cooper and Ross (1998), Peck and Shell (2003) and others, I allow investors to condition their withdrawal decisions on the realization of an extrinsic random variable $s$, which will be called the sunspot state. The sunspot state is unrelated to the fundamentals and has the interpretation of investor sentiment. The realization of $s$ is observed by all investors at the beginning of period 1 and can on take two values, $\alpha$ and $\beta$, with respective probability $1-q$ and $q$. Henceforth, $\alpha$ is labeled the $\operatorname{good}$ state and $\beta$ is labeled the panic state. Thus, I focus on the possibility that when $s=\beta$, it might become optimal for a patient investor to withdraw in period 1 (i.e. to panic) if he expects other patient investors to panic as well. A withdrawal strategy for investor $i$ is a function $y_{i}$ which specifies an action either to withdraw in period 1 or in period 2 - for each possible combination of his preference type $\omega_{i} \in\{0,1\}$, the sunspot state $s \in\{\alpha, \beta\}$ and his position in the order of opportunities to withdraw $l \in[0,1]$ :

$$
y_{i}:\{0,1\} \times\{\alpha, \beta\} \times[0,1] \rightarrow\{0,1\}
$$

where $y_{i}=0$ corresponds to withdrawing in period 1 and $y_{i}=1$ corresponds to withdrawing in period 2. On the other hand, the banks and the government do not observe the realization of the sunspot state. Nevertheless, we will see that in equilibrium banks are able to infer the realization of $s$ after the measure of withdrawals exceeds a certain threshold.

\subsection{Timeline}

At the start of period 0 , investors receive their initial endowment and the government collects taxes by imposing a common tax rate $\tau$ on investors' endowments. Investors then deposit their

\footnotetext{
${ }^{5}$ Taxation with the purpose of funding the deposit insurance plan of the government has been introduced into the Diamond and Dybvig framework by Freeman (1998), Boyd et al. (2002) and Martin (2006). In this paper, following Keister (2015), the government's tax revenues serve a more general purpose since they are used to provide a public good, in addition to bailing out the financial sector.
} 


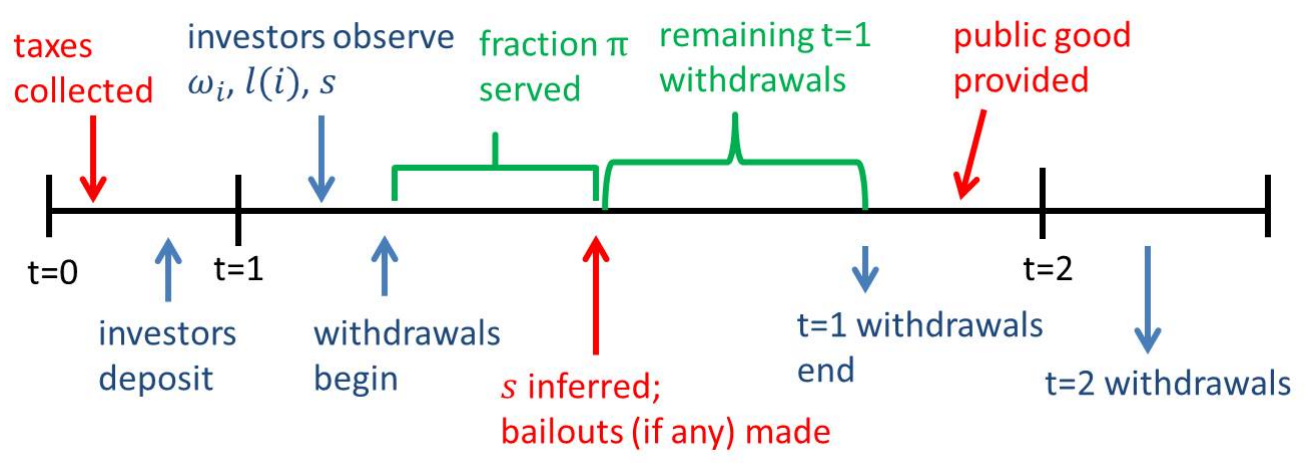

Figure 1: Timeline

after-tax endowment in the banking sector and period 0 ends.

At the beginning of period 1 , each investor $i \in[0,1]$ observes whether he is patient or impatient $\omega_{i} \in\{0,1\}$, his position in the order of opportunities to withdraw $l(i) \in[0,1]$ and the realization of the sunspot state $s \in\{\alpha, \beta\}$. Withdrawals then begin. The environment here is similar to Ennis and Keister (2010). Specifically, each impatient investor always strictly prefers to withdraw in period 1, regardless of the realization of $s$ or his position in the order of opportunities to withdraw. Moreover, given that the fraction of impatient investors in period 1 is always equal to $\pi$, banks are unable to infer the realization of $s$ while the first $\pi$ fraction of withdrawals is being made. Hence, in equilibrium, payments to the first $\pi$ fraction of investors to withdraw cannot be contingent on $s$. After $\pi$ withdrawals, banks will be able to infer the state. In particular, if the state is $\alpha$, there are no more withdrawals in period 1 since all of the impatient investors were able to contact the bank and withdraw. In contrast, if the state is $\beta$ and a run is underway, withdrawals will continue because some impatient investors have not yet been able to withdraw. The government, in this case, has the option of using fraction of the tax revenues in order to make transfers to those (and only those) banks experiencing a run. After any bailouts have been made, the remaining tax revenue is used to provide the public good and period 1 ends 6

In period 2, those patient investors that did withdraw in period 1 receive a pro-rata share of the bank's resources in the final period and the game ends.

\section{Panic equilibrium}

Given the self-fulfilling nature of a run in this model, a no-panic equilibrium, where investors withdraw in period 1 only when they are impatient, always exists. At the same time, another

\footnotetext{
${ }^{6}$ Observe that the central location in period 1 will be contacted only by those demanding to withdraw in period 1 , which, in addition to the fact that there is no aggregate uncertainty about the fraction of truly impatient investors, allows the bank to completely infer the state after the measure of withdrawals reaches $\pi$. Notice that the approach here is different from Green and Lin (2003), where all investors must report to the bank in period 1 .
} 
equilibrium where fraction of the patient investors panic and withdraw in period 1 for certain realizations of the sunspot state may also exist. Equilibrium of the later type will be called a panic equilibrium and will be the focus of this section.

\subsection{A profile of withdrawal strategies}

I focus on equilibria where investors with the same endowment follow the same strategy and I introduce two strategies - the no-panic and the panic strategy. The no-panic strategy is the standard truth-telling behavior in a Diamond and Dybvig model, that is, investors with endowment $e$ are said to follow the no-panic strategy if they choose to withdraw in period 1 only when impatient.

$$
y_{i}^{N P}\left(\omega_{i}, \alpha, l\right)=\omega_{i} \text { for } i \in[0,1] \text { s.t. } E(i)=e
$$

On the other hand, investors with endowment $e$ are said to follow the panic strategy if:

$$
\left\{\begin{array}{c}
y_{i}^{P}\left(\omega_{i}, \alpha, l\right)=\omega_{i} \\
\left.y_{i}^{P}\left(\omega_{i}, \beta, l\right)=\left\{\begin{array}{c}
0 \\
\omega_{i}
\end{array}\right\} \text { if }\left\{\begin{array}{c}
l \leq \pi \\
l>\pi
\end{array}\right\}\right\} \quad \text { for } i \in[0,1] \text { s.t. } E(i)=e
\end{array}\right.
$$

Impatient investors always withdraw in period 1 because they do not derive any utility from consuming in the last period. Patient investors, on the other hand, face a strategic choice. According to (2) when the state is $\alpha$, patient investors with endowment $e$ choose to wait until period 2 to withdraw. In contrast, when the state is $\beta$, patient investors with endowment $e$ choose to withdraw in period 1 when they are among the first $\pi$ fraction of investors with an opportunity to withdraw..$^{7}$ Observe that the strategy profile in (2) specifies that the run stops after $\pi$ withdrawals have taken place and the sunspot state is inferred by the banks. This type of strategy profile was introduced by Ennis and Keister (2010), who showed that in settings where banks are able to react by changing payments when withdrawal demand is high an equilibrium bank run will be necessarily partial and restricted to those investors that can withdraw before banks infer the state.

The government's choice of $\tau$ at the beginning of period 0 leads to a proper subgame associated with this value of the tax rate. Lack of commitment implies that the actions of banks and the government within this subgame are taken after investors have chosen withdrawal strategies and, therefore, must be a best response to those strategies. It will be convenient to characterize the profile of withdrawal strategies by defining $P(\tau)$ as the set of investor types that follow the panic strategy in the subgame for given $\tau$. For example, a panic set of the form

\footnotetext{
${ }^{7}$ The panic strategy in (2) assumes that each investor knows his exact order in the opportunities to withdraw $l \in[0,1]$ during period 1 and this information is used when deciding whether to withdraw in period 1 or wait until period 2. However, all results that will be presented obtain under the weaker assumption according to which each investor only knows whether he is able to withdraw before banks infer the realization of the sunspot.
} 
$P(\tau)=\left[x, e_{H}\right]$ means that investors with endowment in the set $\left[x, e_{H}\right]$ follow the panic strategy, whereas the remaining investor types $\left[e_{L}, x\right)$ follow the no-panic strategy.

\subsection{Type-specific banks}

To begin, I will study equilibrium of the model assuming that investors with the same endowment operate their own liquidity insurance arrangement (i.e. a separate bank for type $e$ investors).

Definition 1. The part of the financial system providing intermediation only to type $e$ investors is called type e banks

Assuming that each type of investor operates its own bank simplifies the analysis. In particular, the intervention of the government can be characterized in terms of a bailout to type $e$ banks, or equivalently, in terms of a bailout to type $e$ investors since there is a one-to-one correspondence between the type of investors and their banks. In reality, financial intermediaries perform maturity transformation for investors with different wealth levels. Notice, however, that "a bank" in this framework should not be interpreted in the usual sense as a separate legal entity, but rather as an equilibrium clustering of investors of the same type within the financial system. In section 5 , the model is augmented to include a bank formation stage in period 0 and I show that, under plausible assumptions about the behavior of financial intermediaries, the structure of the financial sector emerging in equilibrium is equivalent to assuming a separate bank for each type of investors. For this reason, I first present the analysis in the simpler case where this pattern is simply assumed.

The payment schedule for type $e$ investors in the subgame for $\tau$ is summarized in the following vector:

$$
\left(c_{1}(e, \tau), c_{2 \alpha}(e, \tau), c_{1 \beta}(e, \tau), c_{2 \beta}(e, \tau)\right)
$$

The payment given to investors withdrawing before banks infer the state $c_{1}(e, \tau)$ cannot be contingent on $s$. After fraction $\pi$ of withdrawal has taken place, banks infer the state $s$ and reschedule payments in order to reflect this new information. If the state is $\alpha$, all of the remaining investors are patient and each receives $c_{2 \alpha}(e, \tau)$ in period 2 . On the other hand, if the state is $\beta$, each of the remaining impatient investors receives $c_{1 \beta}(e, \tau)$ in period 1 , whereas each of the remaining patient investors receives $c_{2 \beta}(e, \tau)$ in period 2 .

Importantly the payment schedule in (3) is not chosen ex-ante, but rather will be determined as the outcome of a process in which banks updates their payments in order to reflect the arrival of new information in an ex-post optimal way. Given the payment schedule in (3), type $e$ investors will be best responding with the panic strategy in (2) whenever the following set of conditions are satisfied: 


$$
\frac{c_{1}(e, \tau)}{c_{2 \alpha}(e, \tau)}<1 \quad \text { and } \quad \frac{c_{1}(e, \tau)}{c_{2 \beta}(e, \tau)}>1
$$

To see that (4) is sufficient for type $e$ investors to best respond with the panic strategy in (2), consider a patient type $e$ investor with a chance to withdraw before $s$ is inferred by the banks. If $s=\alpha$, the first inequality in (4) ensures that he prefers to wait. On the other hand, if $s=\beta$, the second inequality in (4) ensures that he prefers to withdraw in period 1.

I search for equilibria of the sub-game for given $\tau$ by: $(i)$ fixing a panic set of investor types $P(\tau) \subseteq\left[e_{L}, e_{H}\right]$, (ii) deriving the best response of the banks and the government to this complete profile of withdrawal strategies, (iii) checking whether condition (4) is satisfied for each investor type in the panic set $P(\tau)$, and, finally, (iv) finding the tax rate $\tau^{*}$ in period 0 that yields the highest aggregate expected utility ${ }^{8}$

\subsection{Withdrawals after banks infer $s$}

If type $e$ investors follow the no-panic strategy, then after $\pi$ withdrawals have been made in period 1, all of the remaining investors will be patient, regardless of the state $s$. If we define $\pi_{s}(e)$ to be the fraction of the remaining type $e$ investors who are impatient, we have:

$$
\pi_{\alpha}(e)=0 \quad \text { and } \quad \pi_{\beta}(e)=0
$$

On the other hand, if type $e$ investors follow the panic strategy, we have:

$$
\pi_{\alpha}(e)=0 \quad \text { and } \quad \pi_{\beta}(e)=\pi
$$

If withdrawals stop after reaching a measure of $\pi$, the bank infers that the state is $\alpha$ and therefore the first $\pi$ withdrawals were made only by impatient type $e$ investors, hence $\pi_{\alpha}(e)=$ 0 . If withdrawals continue after $\pi$, the bank infers that the state is $\beta$ and the fraction of the remaining type $e$ investors who are impatient equals $\pi 9^{9}$ Let $\psi_{s}(e, \tau)$ denote the quantity of per capita resources after the bank have serviced a fraction $\pi$ of the investors. If $s=\alpha$ :

$$
\psi_{\alpha}(e, \tau)=(1-\tau) e-\pi c_{1}(e, \tau)
$$

On the other hand, if $s=\beta$ the bank's resources can be potentially augmented by a bailout transfer from the government. Letting $b(e, \tau)$ denote the per capita bailout to a type $e$ bank, we have:

\footnotetext{
${ }^{8}$ Given that the run on each bank is sustained by self-fulfilling expectations, we can always find equilibria where all investors in a given bank follow the no-panic strategy. As a result, investor types outside the panic set will be best responding with the no-panic strategy.

${ }^{9}$ Patient and impatient investors are equally likely to occupy any place in the order of opportunities to withdraw. When the state is $\beta$ and after $\pi$ withdrawals, the fraction of impatient investors who have been served will be equal to $\pi^{2}$, which implies that the remaining fraction of impatient investors will be equal to $\frac{\pi-\pi^{2}}{1-\pi}=\pi$.
} 


$$
\psi_{\beta}(e, \tau)=(1-\tau) e-\pi c_{1}(e, \tau)+b(e, \tau)
$$

The remaining resources of the bank in state $s$ will be distributed efficiently among the remaining investors:

$$
V\left(\psi_{s}(e, \tau) ; \pi_{s}(e)\right)=\max _{c_{1 s}(e, \tau), c_{2 s}(e, \tau)}(1-\pi)\left[\pi_{s}(e) u\left(c_{1 s}(e, \tau)\right)+\left(1-\pi_{s}(e)\right) u\left(c_{2 s}(e, \tau)\right)\right]
$$

subject to the budget constraint in state $s$ :

$$
(1-\pi)\left[\pi_{s}(e) c_{1 s}(e, \tau)+\left(1-\pi_{s}(e)\right) \frac{c_{2 s}(e, \tau)}{R}\right]=\psi_{s}(e, \tau)
$$

where $\pi_{s}(e)$ is determined by (5) if type $e$ follows the no-panic strategy and by (6) if type $e$ follows the panic strategy. The bank's payments after inferring the state will satisfy the following first order condition, where $\mu_{s}(e, \tau)$ is the shadow value on the resources constraint in state $s$ :

$$
\mu_{s}(e, \tau)=u^{\prime}\left(c_{1 s}(e, \tau)\right)=R u^{\prime}\left(c_{2 s}(e, \tau)\right)
$$

The above condition implies that waiting to withdraw in period 2 becomes a dominant strategy for patient investors once banks infer the state and reschedule payments. In other words, as in Ennis and Keister (2010), an equilibrium bank run in this setting is necessarily partial and can only involve investors who are able to withdraw before banks infer the state.

\subsection{Bailouts}

If $s=\alpha$ the government does not intervene in the banking sector and the level of the public good is equal to the tax proceeds $g_{\alpha}(\tau)=\tau$. On the other hand, if $s=\beta$ the government allocates the tax proceeds between the public good and bailouts to banks experiencing a run in order to maximize:

$$
\max _{b(e, \tau) \geq 0} \int_{e \in P(\tau)} V\left((1-\tau) e-\pi c_{1}(e, \tau)+b(e, \tau) ; \pi\right) d G(e)+v(\tau-B(\tau))
$$

The bailout transfer must be non-negative (that is, taxing after period 0 is not allowed) and bailouts will be potentially made only to those banks whose investors follow the panic strategy (i.e. $e \in P(\tau)$ ), since these are the banks that experience a run when $s=\beta$. The public good in state $\beta$ is equal to the remaining tax revenues $g_{\beta}(\tau)=\tau-B(\tau)$, where $B(\tau)$ is the aggregate bailout:

$$
B(\tau)=\int_{e \in P(\tau)} b(e, \tau) d G(e)
$$


Differentiating (12) with respect to $b(e, \tau)$ and taking into account that bailouts must be nonnegative, we obtain:

$$
\mu_{\beta}(e, \tau) \leq v^{\prime}(\tau-B(\tau))
$$

where (14) holds with equality whenever $b(e, \tau)>0$. According to (14), the marginal utility from the private good will be equalized to the marginal utility from the public good in all banks receiving a bailout. In addition, (11) and (14) imply that all banks receiving a bailout will provide the same payment schedule to their remaining investors in state $\beta$, which will be independent of $e$ and henceforth denoted $\left(c_{1 \beta}(\tau), c_{2 \beta}(\tau)\right)$. From (6) and (10) we obtain that $\psi_{\beta}^{B}(\tau)$ - the per-capita level of the resources necessary to deliver this payment schedule - will satisfy:

$$
(1-\pi)\left[\pi c_{1 \beta}(\tau)+(1-\pi) \frac{c_{2 \beta}(\tau)}{R}\right]=\psi_{\beta}^{B}(\tau)
$$

Observe that (14) and (15) imply that $\psi_{\beta}^{B}(\tau)$ is determined by aggregate conditions and is, therefore, treated as exogenous by individual banks. Finally, the bailout transfer to type $e$ banks (when their investors follow the panic strategy) is characterized by:

$$
b(e, \tau)=\max \left\{\psi_{\beta}^{B}(\tau)-\left[(1-\tau) e-\pi c_{1}(e, \tau)\right], 0\right\}
$$

The next result shows that the bailout to a given bank is decreasing in the endowment of its investors:

Proposition 1. (The ex-post optimal bailout policy) Suppose that type $e_{1}$ and type $e_{2}$ investors with $e_{1}<e_{2}$ follow the panic strategy in equilibrium. Then, if either type $e_{1}$ or type $e_{2}$ bank receive a bailout, we have $b\left(e_{1}, \tau\right)>b\left(e_{2}, \tau\right)$

The government's intervention ensures that the payment schedule is the same across all banks that have been bailed out. In equilibrium, banks whose investors have higher initial endowment receive lower bailouts (if any at all), since these banks would also have a higher level of per capita resources before the government's intervention and therefore require less in government transfers in order to deliver the common payment schedule in banks receiving a bailout.

\subsection{Withdrawals before banks infer $s$}

During the first $\pi$ withdrawals, banks are uncertain about the realization of the state $s$ and therefore payments cannot be made contingent $s$. In addition, banks whose investors follow the panic strategy will experience a run when $s=\beta$ and therefore could qualify for a bailout from the government in that state. From (16), a bank experiencing a run in state $\beta$ will be bailed out by the government whenever the quantity of this bank's per-capita resources is 
below $\psi_{\beta}^{B}(\tau)$. Thus, depending on the choice of $c_{1}(e, \tau)$, a type $e$ bank qualifies for a bailout if:

$$
(1-\tau) e-\pi c_{1}(e, \tau)<\psi_{\beta}^{B}(\tau)
$$

and does not qualify if:

$$
(1-\tau) e-\pi c_{1}(e, \tau) \geq \psi_{\beta}^{B}(\tau)
$$

Suppose that type $e$ investors follow the panic strategy. A type $e$ bank that chooses to qualify for a bailout will solve the following program:

$$
W^{B}(e, \tau) \equiv \max _{c_{1}(e, \tau)}\left\{\pi u\left(c_{1}(e, \tau)\right)+(1-q) V\left((1-\tau) e-\pi c_{1}(e, \tau) ; \pi_{\alpha}\right)+q V\left(\psi_{\beta}^{B}(\tau) ; \pi_{\beta}\right)\right\}
$$

subject to (17), which ensures that its choice of $c_{1}(e, \tau)$ will prompt the government to bail out the bank in state $\beta$. On the other hand, a type $e$ bank that chooses not to qualify for a bailout will solve the following program:

$$
W^{N B}(e, \tau) \equiv \max _{c_{1}(e, \tau)}\left\{\begin{array}{c}
\pi u\left(c_{1}(e, \tau)\right)+(1-q) V\left((1-\tau) e-\pi c_{1}(e, \tau) ; \pi_{\alpha}\right) \\
+q V\left((1-\tau) e-\pi c_{1}(e, \tau) ; \pi_{\beta}\right)
\end{array}\right\}
$$

subject to (18), which ensures that its choice of $c_{1}(e, \tau)$ will not prompt the government to bail out the bank in state $\beta$. Henceforth, a bank that solves the program in (20) is said to selfinsure. A fraction $\pi$ of type $e$ investors withdraw before the bank has inferred the state and each one of them receives $c_{1}(e, \tau){ }^{10}$ The second and third terms are characterized by (9) and represent the expected utility for the remaining investors in the bank after the state is inferred and the remaining resources are distributed efficiently. The difference between (19) and (20) is that banks receiving a bailout in state $\beta$ will have the same quantity of per-capita resources in this state $\psi_{\beta}^{B}(\tau)$, which will be determined by economy-wide conditions. Next, define the function:

$$
D(e, \tau) \equiv W^{B}(e, \tau)-W^{N B}(e, \tau)
$$

If $D(e, \tau)>0$, type $e$ banks best respond by qualifying for a bailout, whereas, if $D(e, \tau)<0$, type $e$ banks best respond by self-insuring. Denoting with $c_{1}^{B}(e, \tau)$ the solution to the program in (19) and with $c_{1}^{N B}(e, \tau)$ the solution to the program in (20). The choice of payments during the first $\pi$ withdrawals in banks whose investors follow the panic strategy is characterized below:

Proposition 2. In a subgame for given $\tau$ :

\footnotetext{
${ }^{10}$ Investors are risk averse and therefore every type $e$ bank chooses to give the same payment $c_{1}(e, \tau)$ to all investors withdrawing before $s$ is inferred.
} 
(i) The choice of $c_{1}(e, \tau)$ when type e banks best respond by qualifying for a bailout is characterized by:

$$
u^{\prime}\left(c_{1}^{B}(e, \tau)\right)=(1-q) \mu_{\alpha}^{B}(e, \tau)
$$

(ii) The choice of $c_{1}(e, \tau)$ when type e banks best respond by self-insuring is characterized by:

$$
u^{\prime}\left(c_{1}^{N B}(e, \tau)\right)=(1-q) \mu_{\alpha}^{N B}(e, \tau)+q \mu_{\beta}^{N B}(e, \tau)
$$

A bank that qualifies for a bailout will have the same quantity of per-capita resources in state $\beta$, regardless of its choice of payments to the first $\pi$ investors (as long as its choice satisfies (17)). Hence, a bank that qualifies for a bailout ignores the shadow value of its resources in state $\beta$ and sets early payments according to (22). On the other hand, a bank that selfinsures takes into account that higher $c_{1}(e, \tau)$ leads to a lower level of resources both when the state is $\alpha$ and when the state is $\beta$ and sets the payments to the first $\pi$ investors according to (23), which would ensure that the marginal utility of investors withdrawing before the state is revealed equals the expected shadow value of the bank's resources after the state is known. Henceforth, I restrict the parameters of the model to satisfy:

$$
\begin{gathered}
q<\frac{R-1}{R} \\
\frac{R^{\frac{1-\gamma}{\gamma}}}{\pi+(1-\pi) R^{\frac{1-\gamma}{\gamma}}}<\left(\frac{1-R q}{R-R q}\right)^{\frac{1}{\gamma}}
\end{gathered}
$$

Lemma 1 in the appendix shows that (24) is necessary for the the existence of equilibria where investors in banks qualifying for a bailout best respond with the panic strategy in (2). At the same time, investors in banks that self-insure will best respond with the panic strategy whenever the model parameters satisfy (25). ${ }^{11}$ Next, we can show that if type $e$ banks best respond by qualifying for a bailout, they would also increase the payments to investors withdrawing before $s$ is known.

Proposition 3. For all $\tau$ and $e$, we have $c_{1}^{B}(e, \tau)>c_{1}^{N B}(e, \tau)$

Furthermore, whenever a bank finds it optimal to qualify for a bailout, the increase in the payments to investors withdrawing before $s$ is known will be independent of the actual size of the bailout. This fact can be seen from combining (22) and (23) in order to obtain:

$$
\frac{u^{\prime}\left(c_{1}^{N B}(e, \tau)\right)}{u^{\prime}\left(c_{1}^{B}(e, \tau)\right)}=\frac{\mu_{\alpha}^{N B}(e, \tau)}{\mu_{\alpha}^{B}(e, \tau)}+\frac{q}{(1-q)} \frac{\mu_{\beta}^{N B}(e, \tau)}{\mu_{\alpha}^{B}(e, \tau)}
$$

\footnotetext{
${ }^{11}$ Condition (24) assumes that the probability of the panic state is not too high and is identical to the one in Keister (2015). If (24) does not hold, then the panic strategy in (2) cannot be consistent with equilibrium because investors in banks that are being bailed out in state $\beta$ will have an incentive to run regardless of the realization of $s$.
} 
Observe from (7), (10) and (11) that none of the variables on the right hand side is a function of the bailout to type $e$ banks. Hence, the increase in $c_{1}^{B}(e, \tau)$ relative to $c_{1}^{N B}(e, \tau)$ will be independent of $b(e, \tau)$. The implication is that a bank must anticipate a minimum level of a bailout in order to be willing to choose $c_{1}^{B}(e, \tau)$ and hence incur the subsequent reduction in the payments to the remaining investors when the state turns out to be $\alpha$ and there is no run. In other words, if the bailout payment the bank would receive in state $\beta$ is relatively small, the bank would prefer to self-insure by choosing $c_{1}^{N B}(e, \tau)$. Next, define the function $e^{N B}(\tau)$ :

$$
e^{N B}(\tau) \equiv\left\{\begin{array}{c}
e_{L} \\
z \in\left(e_{L}, e_{H}\right) \text { s.t } D(z, \tau)=0 \\
e_{H}
\end{array}\right\} \quad \text { if } \quad\left\{\begin{array}{c}
D\left(e_{L}, \tau\right) \leq 0 \\
D\left(e_{L}, \tau\right)>0 \text { and } D\left(e_{H}, \tau\right)<0 \\
D\left(e_{H}, \tau\right) \geq 0
\end{array}\right\}
$$

We can show the following:

Proposition 4. (Banks best response for given $\tau$ ) In the subgame for a particular value of $\tau$, let $e^{N B}(\tau)$ be given by (26) and consider banks whose investors follow the panic strategy in (2).

(i) if $e^{N B}(\tau)=e_{L}$, then banks would choose to self-insure

(iii) if $e^{N B}(\tau) \in\left(e_{L}, e_{H}\right)$, then banks with $e<e^{N B}(\tau)$ choose to qualify for a bailout, whereas banks with $e>e^{N B}(\tau)$ choose to self-insure.

(iii) if $e^{N B}(\tau)=e_{H}$, then all banks would choose to qualify for a bailout

In order to see why this result holds, take the derivative of $D(e, \tau)$ with respect to $e$, apply the envelope theorem, and use $c_{1}^{B}(e, \tau)>c_{1}^{N B}(e, \tau)$ to obtain:

$$
\frac{\partial D(e, \tau)}{\partial e}=(1-\tau)\left(u^{\prime}\left(c_{1}^{B}(e, \tau)\right)-u^{\prime}\left(c_{1}^{N B}(e, \tau)\right)\right)<0
$$

hence $D(e, \tau)$ is a strictly decreasing function of $e$ and we obtain the result in Proposition 4 . Ex-ante, each bank has the option to self-insure by solving the program in (20). The desirability of self-insurance will be higher for banks whose investors have higher initial endowment, since they anticipate to receive lower bailouts from the government in case of a run. In addition, we can show that:

$$
\frac{\partial e^{N B}(\tau)}{\partial \tau}>0
$$

For larger values of $\tau$, banks would anticipate larger bailouts and, as a result, larger fraction of them are willing to choose payments which qualify them for a bailout in case they experience a run. That is, the option to self-insure by choosing $c_{1}^{N B}(e, \tau)$ becomes less desirable for a type $e$ bank when the government is expected to provide more generous bailouts in a panic. 


\section{Discussion}

The analysis in this section, specifically the idea that any given bank must decide whether to take actions which will make it eligible for a bailout in the event of a run from its investors, is novel to the literature on financial panics. Moreover, it might initially appear that it can never be optimal for any bank to disqualify itself for a bailout, since a bailout is an inflow of resources, which allows the bank to provide higher payments to its remaining investors. Indeed, for fixed $c_{1}(e, \tau)$, a type $e$ bank will be able to deliver higher ex-ante utility to its investors for any $b(e, \tau)>0$. The crucial observation, however, is that the choice of $c_{1}(e, \tau)$ is affected by the decision of the bank to qualify (or disqualify) itself for a bailout. That is, once a given bank chooses to follow a strategy which secures a bailout in case of a run, it also becomes optimal to aggressively increase payments when there is uncertainty as to whether the run will actually take place. The negative side of obtaining a bailout is precisely this discrete jump in the payments to investors withdrawing before the state is known, which depletes the resources of the bank and thus imposes a cost to the remaining investors when the state is $\alpha$ and the run does not take place.

In addition, while it might be optimal for individual banks to receive a bailout, the cost of the government intervention will be too high from a social perspective. The reason is that banks fail to internalize their collective effect on the level of the public good in state $\beta$ and end up choosing payments which are too high (from the perspective of a social planner) which would increase the cost of a subsequent government intervention during a panic 12

\subsection{Equilibria for fixed $\tau$}

For a particular value of $\tau$, consider a complete profile of withdrawal strategies characterized by a panic set $P(\tau) \subseteq\left[e_{L}, e_{L}\right]$. Each investor type $e$ in the panic set $P(\tau)$ follows the panic strategy in (2) whereas each investor type not in the panic set follows the no-panic strategy in (1). A panic equilibrium is associated with a non-empty panic set of investor types $P(\tau) \neq \emptyset$.

The payment schedule for each investor type that follows the panic strategy is characterized by (6), (10), (11), and (22) if their bank receives a bailout and by (6), (10), (11) and (23) if it does not. The government bailout policy is characterized by (13) - (16). The payment schedule for type $e$ investors in case they follow the no-panic strategy is characterized by (5), (10), (11), and (22). Finally, condition (4) must hold for each investor type that follows the panic strategy, since this would ensure that they are best responding with the panic strategy in (2).

In this section, the dependence of a given equilibrium variable on the panic set of investors is denoted explicitly. That is, I write $z(e, \tau ; P(\tau))$ whenever the equilibrium value of $z$ is a function of $\tau, e$ and $P(\tau)$. From, (10), (11), (22) and (23) we obtain that payments in banks that do not receive a bailout in state $\beta$ - either because their investors follow the no-

\footnotetext{
${ }^{12}$ Keister (2015) analyzes this distortion and policies that aim to correct it in a model in which all investors are identical.
} 
panic strategy or because these banks best respond by self-insuring instead of qualifying for a bailout - do not depend on $P(\tau)$. In fact, the only component of the banks' payments schedule that depends directly on the panic set $P(\tau)$ is the allocation in state $\beta$ in banks that qualify for a bailout i.e. $\left(c_{1 \beta}^{B}(\tau ; P(\tau)), c_{2 \beta}^{B}(\tau ; P(\tau))\right)$.

Observe that having a fraction of the investors follow the panic strategy constitutes a necessary, but not a sufficient condition for bailouts to be made in equilibrium, since, as we saw in section 3.4, each banks will choose whether to qualify for a bailout in the event of a run or, instead, to self-insure. That is, whether or not the equilibrium run on the banks leads to a bailout intervention is an endogenous outcome of the model. So fix $\tau$ and consider an investor type $x$ and a panic set $P=\left[x, e_{H}\right]$ such that the following holds:

$$
\left\{\begin{array}{c}
u^{\prime}\left(c_{1 \beta}^{B}\left(\tau ;\left[x, e_{H}\right]\right)\right)=v^{\prime}\left(\tau-\int_{e \in\left[x, e_{H}\right]} b\left(e, \tau ;\left[x, e_{H}\right]\right) d G\right) \\
D\left(x, \tau ;\left[x, e_{H}\right]\right)>0 \\
c_{1}^{B}(x, \tau) \geq c_{2 \beta}^{B}\left(\tau ;\left[x, e_{H}\right]\right)
\end{array}\right\}
$$

The equation on the first line in (28) implies that the bailout policy of the government is expost optimal when investors with endowment in the set $\left[x, e_{H}\right]$ follow the panic strategy. The inequality on the second line implies that type $x$ banks best respond by qualifying for a bailout, whereas inequality on the third line implies that investors whose endowment is $x$ and who are able to withdraw before banks infer the state would best respond by doing so. Let $X(\tau)$ denote the set of all investor types for which (28) is satisfied in the subgame for $\tau$ :

$$
X(\tau) \equiv\left\{x \in\left(e_{L}, e_{H}\right) \text { s.t. }(28) \text { holds }\right\}
$$

The next proposition shows that each investor type in $X(\tau)$ can be used to construct a panic equilibrium that involves bailouts in state $\beta$ :

Proposition 5. (Panic equilibrium with bailouts) If $x \in X(\tau)$, then there is a panic equilibrium in the subgame for $\tau$ where investors with endowment in $\left[e_{L}, x\right)$ best respond with the no-panic strategy in (1) and investors with endowment in $\left[x, e_{H}\right]$ best respond with the panic strategy in (2). Moreover, this equilibrium involves bailouts when $s=\beta$.

On the other hand, if $X(\tau)$ is empty, then for each $x \in\left(e_{L}, e_{H}\right)$ : either type $x$ banks best respond by choosing to self-insure instead of qualifying for a bailout or type $x$ banks best respond by qualifying for a bailout, but their investors face no incentive to panic in state $\beta$. Nevertheless, a panic equilibrium may still exist provided that we can find a panic set of investor types $P(\tau)=\left[y, e_{H}\right]$ such that the following is satisfied:

$$
\left\{\begin{array}{c}
u^{\prime}\left(c_{1 \beta}^{N B}(y, \tau)\right) \leq v^{\prime}(\tau) \\
D\left(y, \tau ;\left[y, e_{H}\right]\right) \leq 0
\end{array}\right\}
$$

The first inequality in (30) implies that the government would not bail out type $y$ banks when 
they choose to self-insure, whereas, the second inequality implies that type $y$ banks best respond by self-insuring. Next, define $Y(\tau)$ to be the set of all investor types for which (30) is satisfied:

$$
Y(\tau) \equiv\left\{y \in\left(e_{L}, e_{H}\right) \text { s.t. (30) holds }\right\}
$$

The next proposition shows that each element in the set $Y(\tau)$ can be associated with a panic equilibrium such that no-bailouts are made in state $\beta$.

Proposition 6. (Panic equilibrium without bailouts) For each $y \in Y(\tau)$, there exists an equilibrium where investors with endowment $e \in\left[e_{L}, y\right)$ follow the no-panic strategy and investors with endowment $e \in\left[y, e_{H}\right]$ follow the panic strategy. There will be no bailouts in equilibrium.

One question that arises in this setting is the following: which investor types could form a part of an equilibrium run on the banks for a given $\tau$ ? In order to make this question more interesting, I will assume that the panic set $\left[e_{L}, e_{H}\right]$ is not consistent with equilibrium in the subgame for $\tau$ (otherwise, the answer is readily available since the equilibrium where all investors follow the panic strategy will exist). In order to find which investors cannot be part of a run on the banks I need to introduce some additional notation. Define the set of threshold investor types for a given $\tau$ :

$$
T(\tau) \equiv\left\{x \in X(\tau) \text { and } c_{1}^{B}(x, \tau)=c_{2 \beta}^{B}\left(\tau ;\left[x, e_{H}\right]\right)\right\}
$$

Investor type belonging to $X(\tau)$ and that is also indifferent, in state $\beta$, between withdrawing in period 1 before $s$ is inferred and waiting until period 2 to withdraw will be called a threshold investor type. If $T(\tau)$ is non-empty, let $e^{T}(\tau)$ denote the lowest among the threshold endowment types for a given $\tau: 13$

$$
e^{T}(\tau) \equiv\left\{x \in T(\tau) \text { s.t } x \leq x^{\prime} \text { for each } x^{\prime} \in T(\tau)\right\}
$$

We are now ready to characterize the type of investors that could participate in an equilibrium run on the banks for a given value of $\tau$.

Proposition 7. For a fixed $\tau$, suppose that $(i)\left[e_{L}, e_{H}\right]$ is not an equilibrium panic set and (ii) $T(\tau)$ is non-empty. Then an investor type whose endowment belongs to the interval $\left[e_{L}, e^{T}(\tau)\right)$ cannot be part of an equilibrium run on the banks.

The government's bailout policy deters investors whose endowment is sufficiently low from running on the banks as part of equilibrium in the subgame for $\tau$. Moreover, since investors with endowment in $\left[e_{L}, e^{T}(\tau)\right)$ do not panic, there will be no need to bail them out as part of

\footnotetext{
${ }^{13}$ The condition for the uniqueness of the threshold investor type depends in a complicated way on the parameters of the model. Nevertheless, the uniqueness of the threshold investor type is not crucial for the the main insights of the model.
} 
equilibrium. Thus, the bailout policy with respect to these types of investors is similar to deposit insurance in the standard Diamond and Dybvig model where an off-equilibrium promise is enough to eliminate the run at no cost in equilibrium. Unlike in the standard case, however, both the fraction of the investors covered by deposit insurance and their characteristics (i.e. those whose endowment is sufficiently low) will be determined endogenously.

At the same time, a promise of more generous rescue package for investors whose endowment exceeds $e^{T}(\tau)$ in order to deter them from panicking fails to be credible since investors correctly perceive that such a rescue package will not be ex-post optimal for the government. As a result, an equilibrium run on the banks could engulf investors whose endowment exceeds $e^{T}(\tau)$. The last result also shows that a panic equilibrium where investors follow the panic strategy only if their endowment is above a certain threshold was not selected arbitrarily, but instead would arise naturally once we account for the way the government's bailout policy would influences investors' propensity to run on the banks.

\section{Numerical example}

Panic equilibria characterized by a threshold investor type are shown for different values of $\tau$ in panel (a) of figure 2. The tax rate $\tau$ is plotted on the horizontal axes and investors' endowments are plotted on the vertical axes. Endowments are generated by $e=0.5+x$, where $x$ follows a symmetric beta distribution. The remaining parameters of the model are set as follows: $R=3$, $\pi=0.5, \gamma=5, \delta=1$ and $q=0.05 .{ }^{14}$ The threshold investor type $e^{T}(\tau)$ exists and is unique for the range of $\tau$ depicted on the figure. Moreover, panel (b) shows that the tax rate that will, in fact, be chosen by the government also belongs to this range (more on the choice of $\tau$ in the next section). Region $A$ in the figure is between $e^{N B}(\tau)$ and $e_{H}$ and it depicts combinations of $(e, \tau)$ such that type $e$ investors follow the panic strategy and type $e$ banks are not bailed out in state $\beta$. Region $B$ is between $e^{T}(\tau)$ and $e^{N B}(\tau)$ and it depicts combinations of $(e, \tau)$ such that type $e$ investors follow the panic strategy and type $e$ banks receive a bailout in state $\beta$. Region $C$ is between $e_{L}$ and $e^{T}(\tau)$ and it shows combinations of $(e, \tau)$ for which type $e$ investors necessarily follow the no-panic strategy in equilibrium. Observe that higher values of $\tau$ also lead to larger bailouts in a crisis and, as a result, the fraction of investors for which the panic strategy cannot be a best response and the fraction of banks choosing to qualify for a bailout instead of self-insuring are both increasing in $\tau$ (i.e $e^{T}(\tau)$ and $e^{N B}(\tau)$ are increasing in $\tau)$.

\footnotetext{
${ }^{14}$ Numerical investigations suggest that other plausible specifications for the distribution for investors' endowments, like the normal or the exponential distribution yield similar qualitative results.
} 


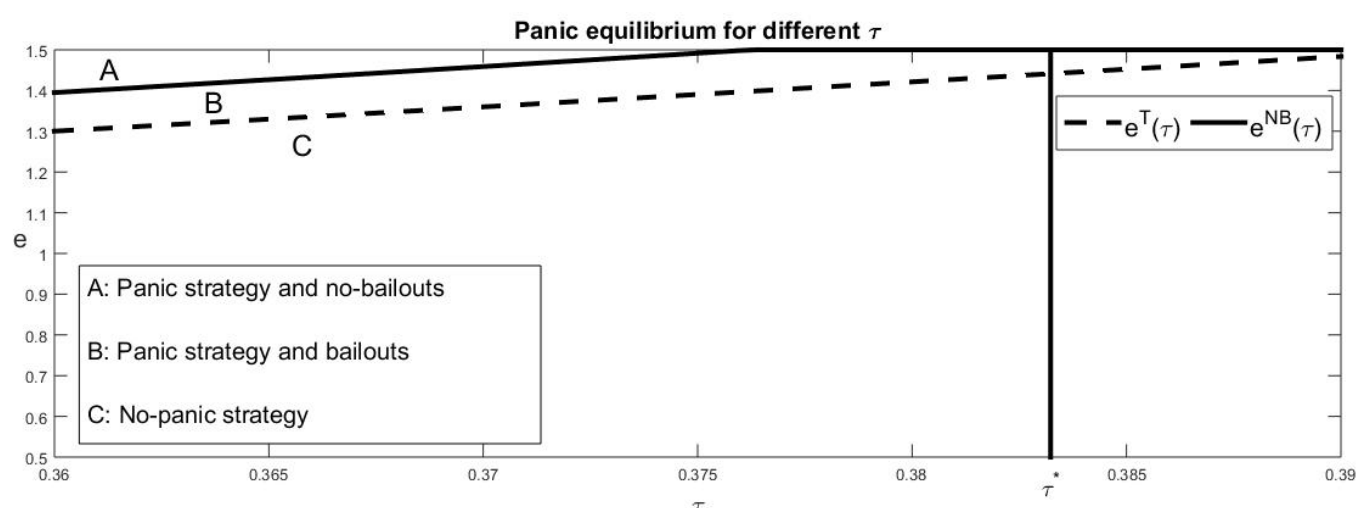

(a)

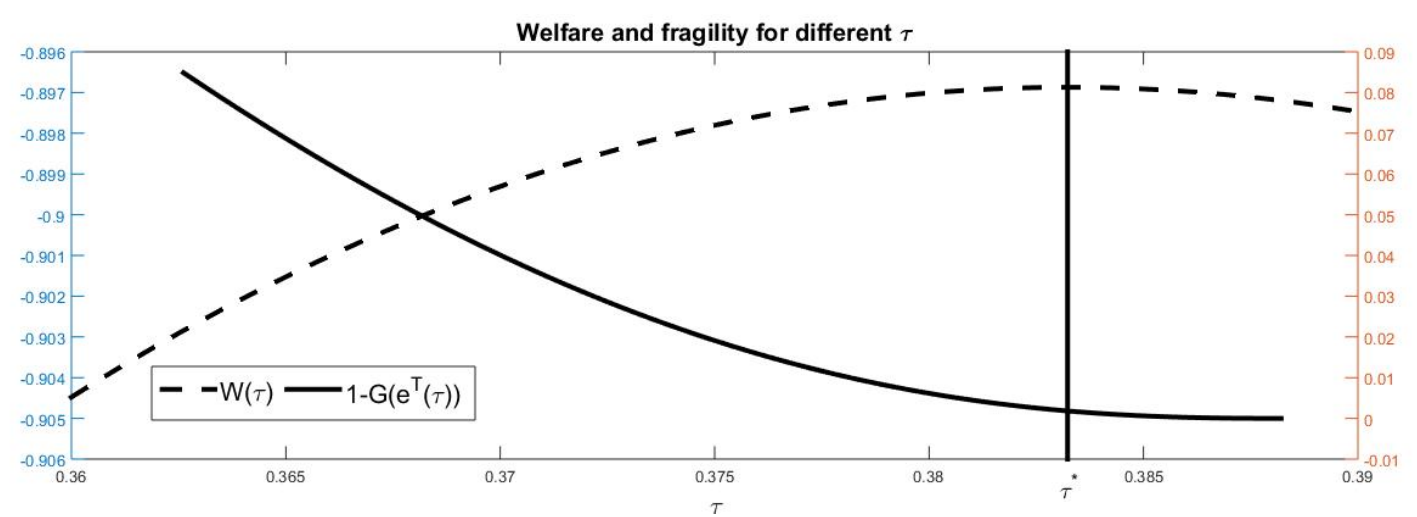

(b)

Figure 2

\subsection{The choice of $\tau$}

For given $\tau$, panel (b) in figure 2 plots the aggregate welfare $W(\tau)$ associated with the panic equilibrium on panel (a).

$$
W(\tau)=\int_{e_{L}}^{e^{T}(\tau)} W^{N P}(e, \tau) d G+\int_{e^{T}(\tau)}^{e^{N B}(\tau)} W^{B}(e, \tau) d G+\int_{e^{N B}(\tau)}^{e^{H}} W^{N B}(e, \tau) d G+E v\left(g_{s}(\tau)\right)
$$

where last term is the expected utility from the public good:

$$
E v\left(g_{s}(\tau)\right)=(1-q) v(\tau)+q v(\tau-B(\tau))
$$

Panel (b) also plots the fraction of investors that are best responding with the panic strategy for given a value of the tax rate $\left(1-G\left(e^{T}(\tau)\right)\right)$. The objective of the government in period 0 is to choose the tax rate associated with the maximum welfare in the resulting subgame. Note that the government is facing a trade-off between protecting the economy from a crisis and efficiently allocation resources during non-crisis times. If the probability of a crisis were zero (i.e. $q=0$ ), the government collects taxes only with the goal of providing the public good. On the other hand, if $q>0$ then an additional dollar in tax revenues become more valuable since 
it can be used to bail out the banks in addition to providing a public good. At the same time, increasing $\tau$ would lead to inefficiently high tax burden when the state is $\alpha$ and the run does not take place. The tax rate chosen by the government $\tau^{*}$ is depicted by the vertical line in both panels and it allows for a fraction of the investors to be best responding with the panic strategy. We have established the following proposition:

Proposition 8. For some parameter values there exists an equilibrium in which a positive fraction of investors follow the panic strategy and bailouts are made to all banks experiencing a run

Hence, we can have an equilibrium in the overall game where some investors panic and run on the banks. Moreover, if such an equilibrium exists, the panic and the subsequent bailouts will be restricted to investors that are relatively wealthy. At the same time, by depressing the level of the public good in state $\beta$, the cost of the bailout would be affecting all agents in the economy.

\section{Inequality and financial fragility}

In this section, the distribution of investors' endowments is restricted to have a two point support $\left\{e_{L}, e_{H}\right\}$, where $e_{H}$ is the endowment of the high-income investors and $e_{L}$ is the endowment of the low-income investors. Investors' endowment are generated in the following way:

$$
e_{L}(\Delta)=1-f \Delta \text { and } e_{H}(\Delta)=1+(1-f) \Delta
$$

where $f \in(0,1)$ denotes the fraction of high-income investors and where the level of inequality is captured by the wealth gap $\Delta \in\left[0, f^{-1}\right)$ between the high and low income investors:

$$
\Delta=e_{H}-e_{L}
$$

Hence, the average endowment is always 1 , there is no wealth inequality when $\Delta=0$ and higher values of $\Delta$ are associated with more unequal wealth distribution. ${ }^{15}$ An economy will be characterized by the following vector of parameter values $(R, \pi, \gamma, \delta, q, f, \Delta)$.

\subsection{Inequality and fragility for fixed $\tau$}

I begin by analyzing the effect of inequality on the nature of financial fragility for a fixed value of $\tau$.

\footnotetext{
${ }^{15}$ Also, note that higher values of $\Delta$ are associated with a mean preserving spread on the distribution of investors' endowments. Equivalently, we can model the case where the top $f$ percent of the population has a fraction $a_{R} \in(0,1)$ of the wealth at the initial period by setting $\Delta\left(a_{R}\right)=\frac{1}{1-f}\left(\frac{a_{R}}{f}-1\right)$.
} 
Proposition 9. In the subgame for given $\tau$ :

(i) there exist $\Delta^{*}$ such that an equilibrium where the low-income investors follow the panic strategy do not exist for $\Delta>\Delta^{*}$.

(ii) there exist $\hat{f}$ and $\hat{\Delta}$ such that equilibrium where the high-income investors follow the panic strategy exists for $\Delta>\hat{\Delta}$ and $f<\hat{f}$.

According to proposition 9, an inequality that is sufficiently high prevents panics from spreading to the low-income investors, and at the same time, makes financial instability more prevalent for those with high-income. The reason for this outcome can be traced to the influence of the government's distributional incentives on the bailout intervention during a crisis. In particular, when inequality is sufficiently high, the haircuts imposed by the government on those with low-income - if they were to become embroiled in a bank run - are not severe enough to allow for the existence of the equilibrium where low-income investors panic. On the other hand, higher inequality would also lead to larger haircuts on high-income investors during a run on the banks, which makes them more prone to panics. Hence, a high wealth gap between the high and the low income investors would ensure the existence of an equilibrium where the former participate in a bank run. In addition, higher levels of inequality implies that the average wealth of an investor benefiting from the government bailouts is also higher.

\subsection{Inequality and the choice of $\tau$}

The government lacks commitment and therefore the only way to influence investors' expectations about the bailout policy is through the choice of $\tau$. For a given value of $\Delta$, denote with $\tau_{L}(\Delta)$ the minimum tax rate necessary to eliminate the equilibria where the low-income investors panic and with $\tau_{H}(\Delta)$ - the minimum tax rate necessary to eliminate the equilibria where the high-income investors panic. That is, for $j=L, H$ :

$$
c_{1}\left(e_{j}(\Delta), \tau\right)<c_{2 \beta}\left(e_{j}(\Delta), \tau\right) \quad \text { iff } \quad \tau>\tau_{j}(\Delta)
$$

we have $\tau_{L}(\Delta)<\tau_{H}(\Delta)$ - eliminating the equilibria where the low-income investors panic requires a lower tax rate since these investors anticipate a more generous support from the government in a crisis. Given the choice of the tax rate $\tau$, there exists an equilibrium where both the high and low income investors follow the panic strategy when $\tau \leq \tau_{L}(\Delta)$. On the other hand, if $\tau_{L}(\Delta)<\tau \leq \tau_{H}(\Delta)$ - an equilibrium where the low-income investors panic would no longer exists. However, the high income investors could still run on the banks in equilibrium. Finally, if $\tau>\tau_{H}(\Delta)$ - neither the high nor the low income investors could run on the banks in equilibrium. For given value of $\Delta$, the government chooses the tax rate in order to maximize the sum of investors' expected utilities from the perspective of period 0 . Let $\tau^{*}(\Delta)$ denote the tax rate chosen by the government when the wealth gap is equal to $\Delta .16$

\footnotetext{
${ }^{16}$ If a given tax rate is consistent with more than one equilibrium, I assume that the equilibrium that obtains involves the largest fraction of investors running on the banks. More complicated selection rules, where each
} 
Figure 3 plots $\tau_{L}(\Delta), \tau^{*}(\Delta)$ and $\tau_{H}(\Delta)$ as functions of the level of inequality in period $0{ }^{17}$ When the wealth gap $\Delta$ between the high and low income investors is relatively small, the government chooses a tax rate which is enough to eliminate the equilibrium where either the high or the low income investors panic. In this situation, bank runs never occur in equilibrium and the optimal tax rate is determined solely by the desired level of the public good. As the wealth gap increases past about $\Delta=0.1$, it is no longer the case that the optimal tax rate based solely on the desired level of the public good is high enough to prevent bank runs by wealthy agents. As the figure shows, the optimal policy is to begin increasing the tax rate $\tau$ as $\Delta$ increases in order to maintain financial stability. At a certain point, however, (about $\Delta=0.17$ in the figure), raising the tax rate further becomes too costly and the government instead chooses to cut the tax rate and permit runs to occur on wealthy investors' banks in state $\beta$. Figure 3 thus provides an example where more unequal wealth distribution is associated with more financial instability.

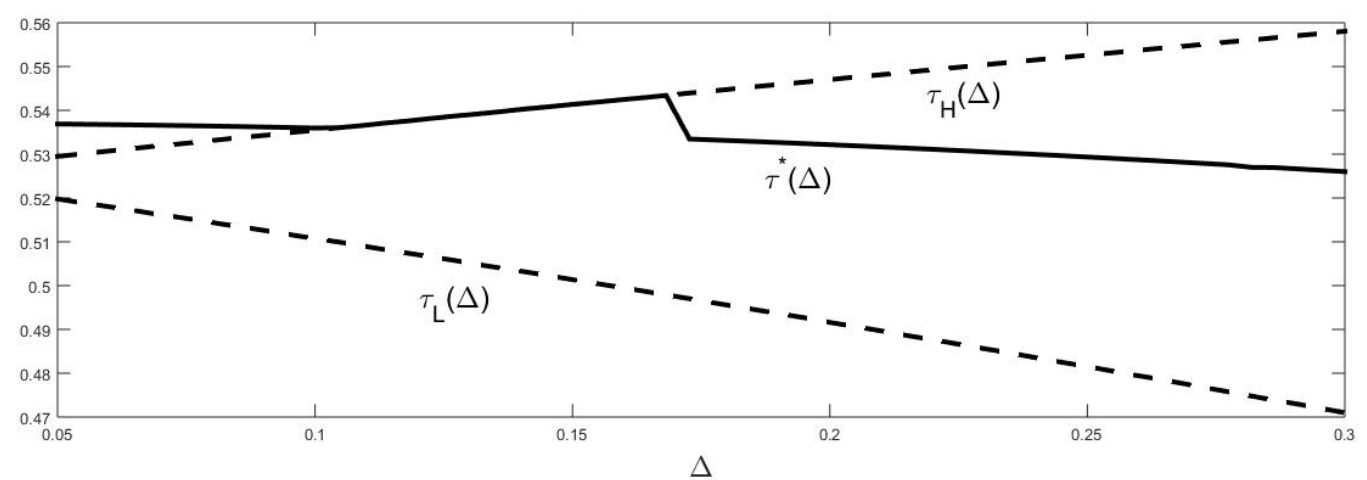

Figure 3: Higher inequality leading to higher fragility

In this framework, however, more unequal wealth distribution does not necessarily lead to more financial instability. In fact, we can show the following:

Proposition 10. There exist economies where more unequal wealth distribution will increase the fragility of the financial system and economies where more unequal wealth distribution will decrease the fragility of the financial system.

Table 1 provides an example where more unequal wealth distribution in period 0 would lower financial fragility by eliminating the equilibrium where the low-income investors panic. ${ }^{18}$ When there is no inequality (i.e $\Delta=0$ ), we have $c_{1}\left(e_{L}, \tau\right)=c_{1}\left(e_{H}, \tau\right)>c_{2 \beta}\left(e_{L}, \tau\right)=c_{2 \beta}\left(e_{H}, \tau\right)$ and therefore the equilibrium where all investors follow the panic strategy exists. However, when the wealth gap increases to $\Delta=0.5$ (the initial endowment of the high-income is 1.5 times that of the low-income) the second row of the table shows that the low-income investors

of the possible equilibria is selected with a given probability, yield qualitatively similar results.

${ }^{17}$ The remaining parameters of the model are set as follows $R=1.5, \pi=0.5, \gamma=5, \delta=1, q=0.05$ and $f=0.5$.

${ }^{18}$ The parameters for the example in table 1 are the following $R=3, \pi=0.5, \gamma=8, \delta=10^{-3}, q=0.05$ and $f=0.5$. 
will not be best responding with the panic strategy and therefore the equilibrium where both the high and low income investors panic in state $\beta$ no longer exist. On the other hand, the third row shows that there is an equilibrium where only the high-income investors follow the panic strategy.

\begin{tabular}{|c|c|c|c|c|c|c|}
\hline Inequality & Panic strategy & $c_{1}\left(e_{L}, \tau\right)$ & $c_{2 \beta}\left(e_{L}, \tau\right)$ & $c_{1}\left(e_{H}, \tau\right)$ & $c_{2 \beta}\left(e_{H}, \tau\right)$ & \\
\hline \hline$\Delta=0$ & high and low income & 0.9838 & 0.8807 & 0.9838 & 0.8807 & \\
\hline$\Delta=0.5$ & high and low income & 0.7834 & 0.8281 & 1.2136 & 0.9760 & \\
\hline$\Delta=0.5$ & high income & 0.7820 & 0.8971 & 1.3056 & 0.9462 & \\
\hline
\end{tabular}

Table 1: Higher inequality leading to lower fragility

\subsection{Costs and benefits of more progressive taxation}

Observe from Figure 3 that the tax rate chosen by the government is lower when inequality is higher except when taxes are kept high with the purpose of deterring high-income investors from panicking. However, if inequality becomes sufficiently high, the government would no longer find it optimal to keep taxes high in order to accomplish this objective and sets $\tau$ in the range consistent with the equilibria where high-income investors run on the banks when the state is $\beta$.

The government wants to lower the tax rate when inequality is increasing because the lowincome investors will have higher marginal utility from private consumption, and therefore, imposing the same tax rate will be more costly from the perspective of the government. Therefore, by shifting the burden of taxation towards the high-income investors, a more progressive tax system in period 0 will not only have a utilitarian benefit in terms of reduced inequality, but could also prevent a decline in tax revenue and therefore preserve the capacity of the government to rescue the financial system in a crisis. However, the link between a more progressive tax system and financial fragility is subtle since we must take into account how inequality is related to financial fragility. In this framework, policies to combat the rise in inequality must incorporate the fact that more unequal wealth distribution could be associated with either an increase or a decrease in the level of financial fragility (an implication of proposition 10).

For the case where a more progressive tax system has an added benefit of increased financial stability consider Figure 3. A progressive tax system, in this case, could prevent a raise in inequality beyond the level allowing for equilibria where the high-income investors follow the panic strategy. On the other hand, a case where more progressive tax system has an added cost in terms of financial instability is shown in Table 1, where a highly progressive tax system imposes an additional distortion, since the equilibria where the low-income investors panic exist when inequality is at low levels.

To summarize: higher inequality combined with the government's utilitarian incentives would render financial panics easier to obtain for the high-income and harder to obtain for 
the low-income investors. Thus, the answer to the question of whether a period of widening inequality has the potential to increase or to decrease financial fragility hinges on whether the financial system is currently admitting equilibria where low-income investors panic and run on the banks. The answer to the previous question, at the same time, would influence the government's desired levels of tax progressivity.

\section{Bank formation stage}

The results in the previous sections were obtained under the assumption that investors with different endowments operate separate intermediation shames (type $e$ bank for type $e$ investors). In this section the model is augmented with a bank formation stage, which allows investors to choose where to deposit their endowment. The goal is to characterize conditions which imply that restricting attention to a separate bank for each investor type is without loss of generality.

\subsection{Coalitions}

In period 0 the government will collect taxes and then investors form coalitions. Coalitions are indexed by $k \in[0,1]$ and each investor can be part of at most one coalition. Each coalition is formed with the goal of creating an intermediation scheme (a bank). The bank is operating to maximize the sum of its investors' expected utilities at any point in time and must infer the realization of the sunspot state $s$ from the withdrawal demand of its investors. In addition, the process of coalition formation is assumed to best respond, instead of trying to influence investors' withdrawal strategy. As before, I restrict attention to equilibria where investors with the same endowment follow the same withdrawal strategy. Let $\Omega_{k}$ denote the set of investor types $e$ that become members of coalition $k$. A coalitional structure will be denoted by $\Omega \equiv\left\{\Omega_{k}\right\}_{k=0}^{1}$. In order to preserve the competitive nature of the banking sector, I restrict attention to competitive coalitional structures where no single coalition has the capacity to influence economy-wide outcomes and I assume that all coalitions that can potentially form are competitive. The payment schedule for type $e$ investor in coalition $k$ is denoted $C^{k}(e, \tau)$ :

$$
C_{k}(e, \tau) \equiv\left(c_{1}^{k}(e, \tau), c_{2 \alpha}^{k}(e, \tau), c_{1 \beta}^{k}(e, \tau), c_{2 \beta}^{k}(e, \tau)\right)
$$

and the collection of the payments schedules for all investor types in coalition $k$ will be denoted $C_{k}(\tau) \equiv\left\{C_{k}(e, \tau)\right\}_{e \in \Omega_{k}}$. The expected utility from private consumption for a type $e$ investor from becoming a member of coalition $k$ is thus:

$$
W_{k}(e, \tau)=\pi u\left(c_{1}^{k}(e, \tau)\right)+(1-q)(1-\pi) u\left(c_{2 \alpha}^{k}(e, \tau)\right)+q(1-\pi)\left(\pi_{\beta}(e) u\left(c_{1 \beta}^{k}(e, \tau)\right)+\left(1-\pi_{\beta}(e)\right) u\left(c_{2 \beta}^{k}(e, \tau)\right)\right)
$$


where $\pi_{\beta}(e)=0$ if type $e$ investors follow the no-panic withdrawal strategy and $\pi_{\beta}(e)=\pi$ if type $e$ investors follow the panic withdrawal strategy. In state $\beta$, coalitions that among their members have investors following the panic strategy will be experiencing a run and will be eligible for a bailout transfer from the government. Let $b_{k}(\tau) \geq 0$ denote the per-capita bailout to coalition $k$. The payments to the remaining investors in coalitions with a bailout will be mandated by the government in order to ensure the ex-post efficient allocation of consumption across the private and the public good:

$$
\begin{gathered}
c_{2 \beta}^{k}(e, \tau)=\min \left\{c_{2 \beta}^{G}(\tau), c_{2 \alpha}^{k}(e, \tau)\right\} \\
u^{\prime}\left(c_{1 \beta}^{k}(e, \tau)\right)=R u^{\prime}\left(c_{2 \beta}^{k}(e, \tau)\right) \\
u^{\prime}\left(c_{1 \beta}^{G}(\tau)\right)=v^{\prime}\left(\tau-\int_{0}^{1} b_{k}(\tau) d k\right)
\end{gathered}
$$

The government mandated payments are restricted not to exceed the payments to patient investors in case their coalition was not experiencing a run, i.e. $c_{2 \beta}^{k}(e, \tau) \leq c_{2 \alpha}^{k}(e, \tau)$ for $e \in \Omega_{k}$. That is, the possibility where some investors benefit from a run on the banks is not allowed. At the same time, the remaining components of the payment schedule in each coalition are restricted to satisfy a proportional rule: for $\left\{e_{1}, e_{2}\right\} \subseteq \Omega_{k}$ :

$$
\frac{c_{1}^{k}\left(e_{1}, \tau\right)}{c_{1}^{k}\left(e_{2}, \tau\right)}=\frac{c_{2 \alpha}^{k}\left(e_{1}, \tau\right)}{c_{2 \alpha}^{k}\left(e_{2}, \tau\right)}=\frac{e_{1}}{e_{2}}
$$

In addition, if the coalition is not bailed out, the payment schedule in state $\beta$ must also obey this rule:

$$
\frac{c_{1 \beta}^{k}\left(e_{1}, \tau\right)}{c_{1 \beta}^{k}\left(e_{2}, \tau\right)}=\frac{c_{2 \beta}^{k}\left(e_{1}, \tau\right)}{c_{2 \beta}^{k}\left(e_{2}, \tau\right)}=\frac{e_{1}}{e_{2}} \quad \text { if } \quad b_{k}(\tau)=0
$$

Observe that this proportional rule will hold trivially when all investors in a given coalition have the same endowment. In addition, (43) implies that all patient investors within the coalition receive the same rate of return on their deposit if their coalition does not experience a run.

Definition 2. A coalition $k$ follows the proportional rule if for $\left\{e_{1}, e_{2}\right\} \subseteq \Omega_{k}$ the payment schedules for type $e_{1}$ and type $e_{2}$ investors - $C_{k}\left(e_{1}, \tau\right), C_{k}\left(e_{2}, \tau\right)$ - satisfy:

(i) (43) - (44) when $b_{k}(\tau)=0$

(ii) (40) - (43) when $b_{k}(\tau)>0$

Henceforth, I restrict attention to coalitions which follow the proportional rule. 


\subsection{Endogenous segmentation of the banking sector}

A coalitional structure $\Omega$ is stable (alternatively belongs to the core), if no coalition within this structure is blocked. A given coalition $\Omega_{k} \in \Omega$ is blocked whenever a new coalition can be formed that would make a fraction of the investors in $k$ strictly better of in terms of expected utility in period 0.19 Next, I denote with

$$
C_{S}(e, \tau) \equiv\left(c_{1}^{S}(e, \tau), c_{2 \alpha}^{S}(e, \tau), c_{1 \beta}^{S}(e, \tau), c_{2 \beta}^{S}(e, \tau)\right)
$$

the payment schedule for type $e$ investors when they operate an intermediation scheme on their own and with $W_{S}(e, \tau)$ - the expected utility from private consumption in period 0 associated with the payment schedule in (45). As in section $3, C_{S}(e, \tau)$ will be characterize by (10) - (11), (14) - (15) and (22) if the government intervenes and provides a bailout in state $\beta$ and by (10) - (11) and (23) otherwise. Note that a necessary condition for a given coalitional structure $\Omega$ to be stable is that for each $\Omega_{k} \in \Omega$ and for each $e \in \Omega_{k}$ we have:

$$
W_{k}(e, \tau) \geq W_{S}(e, \tau)
$$

Next, let $\Omega^{*} \equiv\left\{\Omega_{k}^{*}\right\}_{k=0}^{1}$ be a stable coalition structure and let $\left\{C_{k}^{*}(\tau)\right\}_{k=0}^{1}$ be the collection of payment schedules associated with $\Omega^{*}$ ( where $C_{k}^{*}(\tau)=\left\{C_{k}^{*}(e, \tau)\right\}_{e \in \Omega_{k}}$ ). Denote with $\left\{C_{S}(e, \tau)\right\}_{e \in\left[e_{L}, e_{H}\right]}$ the collection of payment schedules associated with a separate coalition for each investor type. I will refer to the coalition structure $\Omega$ as being payoff-equivalent to a separate coalition for each investor type if for each $e \in\left[e_{L}, e_{H}\right]$ and $C_{k}(e, \tau) \in\left\{C_{k}(\tau)\right\}_{k=0}^{1}$ we have $C_{k}(e, \tau)=C_{S}(e, \tau)$. We are now ready to state the main result of this section.

Proposition 11. (Payoff-equivalence) If $\Omega^{*}$ is a stable coalition structure, then $\Omega^{*}$ is payoffequivalent to a separate coalition for each investor type

In other words, restricting attention to type-specific banks, as was done in Sections 3 and 4, is without loss of generality. The intuition for Proposition 11 is the following: a given coalition involving investors that follow different withdrawal strategies will be blocked by a coalition that involves only those investors following the no-panic strategy. At the same time, any coalition involving investors who follow the same withdrawal strategy (either the panic or the no-panic) behaves as if each investor type within the coalition was operating their own liquidity insurance arrangement (a type $e$ bank for type $e$ investors).

Before concluding this section, observe that, even though the proportional rule might be a reasonable way to model bank's behavior, especially in environments with limited commitment where more complicated rules could fail to be credible, we can formulate a number of

\footnotetext{
${ }^{19}$ This blocking criteria (also called objections criteria) is widely used in the literature on coalition formation to reduce the set of admissible outcomes of the coalition formation process (Ray and Vohra 2015 provide a survey of the relevant literature). In this setting, a stable coalition structure also satisfies the farsighted refinement of the blocking criteria introduced by Harsanyi (1974).
} 
other mechanisms designed to allocate consumption to the investors. Nonetheless, in order to preserve the main massage of the paper, we do not require strict banking segmentation, but rather, two conditions, both of which are empirically relevant: (i) a financial system where investors' claim on intermediaries is positively correlated with their wealth, and (ii) a government that is able to channel funds to specific investors based on their observable characteristics (i.e. wealth).

\section{Conclusion}

I have presented a model of financial intermediation in which the government is unable to commit to the details of the bailout intervention before the the crisis and where investors have different wealth levels. I showed that an equilibrium where wealthy investors run on the banks and prompt the government to bail them out can arise naturally in setting such as these. The reason for this outcome is that the rescue program of the government will be motivated, at least in part, by distributional incentives and will induce endogenous caps to deposit insurance. These caps, in turn, will be decreasing as a function of investors' wealth levels. Thus, the model predicts that financial institutions with wealthy investors will be more likely to benefit from bailouts - an outcome occurring in the absence of any political rent-seeking frictions and under a government that is both benevolent and utilitarian.

If inequality is higher, then the government's distributional incentives during the implementation of the bailout program will also become more pronounced which, in turn, increases wealthy investors' incentive to panic. In settings such as these, a more progressive tax code could lower the level of inequality and prevent equilibria where wealthy investors end up engulfed in a banking panic. Furthermore, a government that is able to use a more progressive tax code in order to shift the burden of taxation towards the wealthy will be less eager to cut taxes when inequality is higher. Hence, by preventing a decline in the government's tax revenue and preserving the government's capacity to rescue the financial system in a crisis, a more progressive tax code could have a prudential effect on financial stability. However, the same distributional incentives of the government imply that effect of inequality on financial fragility is not straightforward. In some cases, higher inequality could actually increase financial stability, since those parts of the financial system providing intermediation to the relatively poor would benefit from a more generous government support in a crisis and might no longer be susceptible to self-fulfilling runs.

The framework in this paper also accounted for the moral hazard issues stemming from the bailout intervention in a crisis. In particular, banks that anticipate to be bailed out ignore the cost that will be imposed on the public sector in a financial panic and as a result engage in excessive levels of maturity transformation. At the same time, a novel aspect of the approach followed here is that a run on a given bank will constitutes a necessary but not a sufficient 
condition for a government intervention. In fact, a given bank would anticipate the conditions leading the government to bail it it out and would decide ex-ante whether to qualify for a bailout in case of a run from its investors. That is, whether or not a financial panic also leads to government intervention is an endogenous outcome of the model.

I conclude by outlining three potentially promising directions for future research. First, one of the tacit assumptions in the paper is that the financial system is relatively transparent and allows the government to determine investors' wealth before the implementation of the bailout policy. However, given the main massage of the paper - namely that the most sizable haircuts in a financial crisis would tend to be imposed on the wealthy - those investors would also be eager to find ways to increase the opacity of the financial system and to make it harder for the government to implement its desired bailout intervention. Second, preventing contagion is often given as one of the primary reasons for the government's rescue program. Extending the model to account for this additional dimension implies that the government must balance its distributional concerns with its desire to prevent contagion. Third, in this model, appointing a bailout authority that is more inclined to rescue financial institutions with wealthy investors (rather than being strictly utilitarian) could, in some cases, eliminate the equilibria where they panic and require subsequent government support - an outcome which would benefit all agents. This implication is, in fact, similar to the literature on the optimal monetary policy where appointing a central banker whose commitment to fight inflation is stronger than that of the public could be beneficial and increase equilibrium welfare (Rogoff 1985). However, such a policy could introduce other distortions to the extent that this person or agency has the ability to influence policy decisions in normal times. Exploring these dimensions of the model is an interesting topic for future research. 


\section{Appendix A: Proof of Selected Propositions}

\section{Proposition 1.}

Proof. First, suppose that both type $e_{1}$ and type $e_{2}$ banks best respond by qualifying for a bailout. The payment schedule for type $e_{1}$ and type $e_{2}$ investors in this case will be determined by (10), (11) and (22). Whereas the bailout to type $e_{1}$ and type $e_{2}$ banks by (16). In order to establish the desired result, it is sufficient to show:

$$
c_{1}\left(e_{1}, \tau\right)<c_{1}\left(e_{2}, \tau\right) \text { for } e_{1}<e_{2}
$$

since, (16) will then imply that $b\left(e_{1}, \tau\right)>b\left(e_{2}, \tau\right)$. The proof is by contradiction. Assume it were the case that $c_{1}\left(e_{1}, \tau\right) \geq c_{1}\left(e_{2}, \tau\right)$, then since $e_{1}<e_{2}$ we have:

$$
(1-\tau) e_{1}-\pi c_{1}\left(e_{1}, \tau\right)<(1-\tau) e_{1}-\pi c_{1}\left(e_{2}, \tau\right)
$$

Given that both type $e_{1}$ and type $e_{2}$ follow the panic strategy, (6) implies that $\pi_{\alpha}\left(e_{1}\right)=\pi_{\alpha}\left(e_{2}\right)$ and $\pi_{\beta}\left(e_{1}\right)=\pi_{\beta}\left(e_{2}\right)$ and we obtain from the budget constraint in state $\alpha$ :

$$
c_{2 \alpha}\left(e_{1}, \tau\right)<c_{2 \alpha}\left(e_{2}, \tau\right)
$$

The first order condition in (11) implies:

$$
\mu_{\alpha}\left(e_{1}, \tau\right)>\mu_{\alpha}\left(e_{2}, \tau\right)
$$

Then from (22) we obtain $c_{1}\left(e_{1}, \tau\right)<c_{1}\left(e_{2}, \tau\right)$ - a contradiction since we initially assumed that $c_{1}\left(e_{1}, \tau\right) \geq c_{1}\left(e_{2}, \tau\right)$. Therefore we must have:

$$
c_{1}\left(e_{1}, \tau\right)<c_{1}\left(e_{2}, \tau\right)
$$

and we obtain the desired result from (16), namely $e_{1}<e_{2}$ implies $b\left(e_{1}, \tau\right)>b\left(e_{2}, \tau\right)$.

Second, proposition 4 implies that type $e_{1}$ banks would best respond by qualifying for a bailout whenever type $e_{2}$ best respond by qualifying for a bailout. Therefore, either only type $e_{1}$ banks qualify for a bailout, in which case $b\left(e_{1}, \tau\right)>0=b\left(e_{2}, \tau\right)$. Or both banks qualify for a bailout, in which case we have established $b\left(e_{1}, \tau\right)>b\left(e_{2}, \tau\right)$.

\section{Proposition 2.}

Proof. Denote with $C_{B}(e, \tau)$ the set of all possible payments during the first $\pi$ withdrawals for which a type $e$ bank will qualify for a bailout when experiencing a run.

$$
C_{B}(e, \tau)=\left\{c_{1}(e, \tau) \text { s.t. }(1-\tau) e-\pi c_{1}(e, \tau)<\psi_{\beta}^{B}(\tau)\right\}
$$

The optimal choice of $c_{1}(e, \tau)$ when qualifying for a bailout solves the following program: 


$$
W^{B}(e, \tau)=\max _{c_{1}(e, \tau) \in C_{B}(e, \tau)}\left\{\pi u\left(c_{1}(e, \tau)\right)+(1-q) V\left((1-\tau) e-\pi c_{1}(e, \tau) ; \pi_{\alpha}\right)+q V\left(\psi_{\beta}^{B}(\tau) ; \pi_{\beta}\right)\right\}
$$

Next, denote with $C_{N B}(e, \tau)$ the set of all possible payments for which a type $e$ bank will not qualify for bailout when experiencing a run (i.e. it self-insures):

$$
C_{N B}(e, \tau)=\left\{c_{1}(e, \tau) \text { s.t. }(1-\tau) e-\pi c_{1}(e, \tau) \geq \psi_{\beta}^{B}(\tau)\right\}
$$

The optimal choice of $c_{1}(e, \tau)$ in this case solves the following program:

$$
W^{N B}(e, \tau)=\underset{c_{1}(e, \tau) \in C_{N B}(e, \tau)}{\operatorname{argmax}}\left\{\begin{array}{c}
\pi u\left(c_{1}(e, \tau)\right)+(1-q) V\left((1-\tau) e-\pi c_{1}(e, \tau) ; \pi_{\alpha}\right) \\
+q V\left((1-\tau) e-\pi c_{1}(e, \tau) ; \pi_{\beta}\right)
\end{array}\right\}
$$

If $c_{1}^{B}(e, \tau)$ is characterized by (22) and if $c_{1}^{N B}(e, \tau)$ is characterized by (23), then Proposition 4 would imply $c_{1}^{N B}(e, \tau)<c_{1}^{B}(e, \tau)$ and, in order to establish the desired result, we must consider three cases.

Case 1: $c_{1}^{B}(e, \tau)$ triggers a bailout, whereas $c_{1}^{N B}(e, \tau)$ would not trigger a bailout:

$$
(1-\tau) e-\pi c_{1}^{B}(e, \tau)<\psi_{\beta}^{B}(\tau)<(1-\tau) e-\pi c_{1}^{N B}(e, \tau)
$$

Then, a type $e$ bank best responding by qualifying for a bailout sets $c_{1}(e, \tau)$ as in (22), given that this is the optimal choice of $c_{1}(e, \tau)$ without the additional constraint $c_{1}(e, \tau) \in C_{B}(e, \tau)$. Similarly, a type $e$ bank best responding by self-insuring would set $c_{1}(e, \tau)$ as in (23) given that this is the optimal choice of $c_{1}(e, \tau)$ without imposing the constraint $c_{1}(e, \tau) \in C_{N B}(e, \tau)$.

Case 2: Both $c_{1}^{B}(e, \tau)$ and $c_{1}^{N B}(e, \tau)$ would trigger a bailout:

$$
(1-\tau) e-\pi c_{1}^{B}(e, \tau)<(1-\tau) e-\pi c_{1}^{N B}(e, \tau)<\psi_{\beta}^{B}(\tau)
$$

If a type $e$ bank is self-insuring, then $\hat{c}_{1}^{N B}(e, \tau)$ must be set to satisfy:

$$
(1-\tau) e-\pi \hat{c}_{1}^{N B}(e, \tau) \geq \psi_{\beta}^{B}(\tau)
$$

hence $\hat{c}_{1}^{N B}(e, \tau)<c_{1}^{N B}(e, \tau)$. I show that in this case type $e$ banks strictly prefer to qualify for a bailout. Indeed, consider the following:

$$
\begin{gathered}
\pi u\left(c_{1}^{B}(e, \tau)\right)+(1-q) V\left((1-\tau) e-\pi c_{1}^{B}(e, \tau) ; \pi_{\alpha}\right)+q V\left(\psi_{\beta}^{B}(\tau) ; \pi_{\beta}\right) \\
> \\
\pi u\left(c_{1}^{N B}(e, \tau)\right)+(1-q) V\left((1-\tau) e-\pi c_{1}^{N B}(e, \tau) ; \pi_{\alpha}\right)+q V\left(\psi_{\beta}^{B}(\tau) ; \pi_{\beta}\right) \\
\geq \\
\pi u\left(c_{1}^{N B}(e, \tau)\right)+(1-q) V\left((1-\tau) e-\pi c_{1}^{N B}(e, \tau) ; \pi_{\alpha}\right)+q V\left((1-\tau) e-\pi c_{1}^{N B}(e, \tau) ; \pi_{\beta}\right) \\
> \\
\pi u\left(\hat{c}_{1}^{N B}(e, \tau)\right)+(1-q) V\left((1-\tau) e-\pi \hat{c}_{1}^{N B}(e, \tau) ; \pi_{\alpha}\right)+q V\left((1-\tau) e-\pi \hat{c}_{1}^{N B}(e, \tau) ; \pi_{\beta}\right)
\end{gathered}
$$


The first inequality follows from the fact that $c_{1}^{B}(e, \tau)$ is the optimal unconstrained choice of $c_{1}(e, \tau)$ when the bank is bailed out (and therefore $\psi_{\beta}^{B}(\tau)$ is treated as exogenous by the bank). The second inequality follows from the assumption that setting $c_{1}^{N B}(e, \tau)$ as in (23) leads to $(1-\tau) e-\pi c_{1}^{N B}(e, \tau)<\psi_{\beta}^{B}(\tau)$. The third inequality from the fact that $c_{1}^{N B}(e, \tau)$ is the optimal choice of early payments when the bank is not bailed out and there are no additional restrictions on the choice of $c_{1}(e, \tau)$. Therefore, type $e$ banks would best respond by qualifying for a bailout and their choice of $c_{1}(e, \tau)$ will be characterized by (22).

Case 3: Both $c_{1}^{B}(e, \tau)$ and $c_{1}^{N B}(e, \tau)$ would not trigger a bailout

$$
(1-\tau) e-\pi c_{1}^{N B}(e, \tau) \geq(1-\tau) e-\pi c_{1}^{B}(e, \tau) \geq \psi_{\beta}^{B}(\tau)
$$

Therefore, in order for a type $e$ bank to qualify for a bailout, it needs to set $\hat{c}_{1}^{B}(e, \tau)$ such that:

$$
(1-\tau) e-\pi \hat{c}_{1}^{B}(e, \tau)<\psi_{\beta}^{B}(\tau)
$$

and we have $\hat{c}_{1}^{B}(e, \tau)>c_{1}^{B}(e, \tau)$. But this would also imply that type $e$ banks are strictly better off by self-insuring. Indeed, consider the following:

$$
\begin{gathered}
\pi u\left(c_{1}^{N B}(e, \tau)\right)+(1-q) V\left((1-\tau) e-\pi c_{1}^{N B}(e, \tau) ; \pi_{\alpha}\right)+q V\left((1-\tau) e-\pi c_{1}^{N B}(e, \tau) ; \pi_{\beta}\right) \\
> \\
\pi u\left(c_{1}^{B}(e, \tau)\right)+(1-q) V\left((1-\tau) e-\pi c_{1}^{B}(e, \tau) ; \pi_{\alpha}\right)+q V\left((1-\tau) e-\pi c_{1}^{B}(e, \tau) ; \pi_{\beta}\right) \\
\geq \\
\pi u\left(c_{1}^{B}(e, \tau)\right)+(1-q) V\left((1-\tau) e-\pi c_{1}^{B}(e, \tau) ; \pi_{\alpha}\right)+q V\left(\psi_{\beta}^{B}(\tau) ; \pi_{\beta}\right) \\
> \\
\pi u\left(\hat{c}_{1}^{B}(e, \tau)\right)+(1-q) V\left((1-\tau) e-\pi \hat{c}_{1}^{B}(e, \tau) ; \pi_{\alpha}\right)+q V\left(\psi_{\beta}^{B}(\tau) ; \pi_{\beta}\right)
\end{gathered}
$$

Neither $c^{N B}(e, \tau)$ nor $c^{B}(e, \tau)$ leads to a bailout in state $\beta$. However, $c^{N B}(e, \tau)$ is also the unconstrained optimal choice of $c(e, \tau)$ when type $e$ banks self-insure and therefore we obtain the first inequality. The second inequality follows from $(1-\tau) e-\pi c_{1}^{B}(e, \tau) \geq \psi_{\beta}^{B}(\tau)$. Whereas the third inequality follows from the fact that $c^{B}(e, \tau)$ is the unconstrained optimal choice of early payments when $\psi_{\beta}^{B}(\tau)$ is viewed as exogenous by the bank. Therefore, type $e$ banks best respond by choosing to self-insure and will set $c_{1}(e, \tau)$ as in (23).

The discussion in section 3.5, in particular, conditions (24) and (25) rely on the following lemma.

\section{Lemma 1.}

Proof. Suppose that type $e$ banks best respond by qualifying for a bailout in state $\beta$, then $c_{1}(e, \tau)$ is characterized by (22), combined with (11) this yields: 


$$
u^{\prime}\left(c_{1}^{B}(e, \tau)\right)=(1-q) R u^{\prime}\left(c_{2 \alpha}^{B}(e, \tau)\right)
$$

A necessary condition for the panic strategy in (2) to be a best respond is $c_{2 \alpha}^{B}(e, \tau)>c_{1}^{B}(e, \tau)$, which is the case whenever:

$$
q<\frac{R-1}{R}
$$

but this is the same as condition (24). On the other hand, suppose that type $e$ banks best respond by self-insuring. By combining (23) with (11) we obtain:

$$
u^{\prime}\left(c_{1}^{N B}(e, \tau)\right)=(1-q) R u^{\prime}\left(c_{2 \alpha}^{N B}(e, \tau)\right)+q R u^{\prime}\left(c_{2 \beta}^{N B}(e, \tau)\right)
$$

Next, if type $e$ investors best respond with the panic strategy, we must have $c_{1}^{N B}(e, \tau)>$ $c_{2 \beta}^{N B}(e, \tau)$. From from (23) and (11), this is equivalent to:

$$
(1-q) R u^{\prime}\left(c_{2 \alpha}^{N B}(e, \tau)\right)+q R u^{\prime}\left(c_{2 \beta}^{N B}(e, \tau)\right)<u^{\prime}\left(c_{2 \beta}^{N B}(e, \tau)\right)
$$

or equivalently:

$$
\frac{u^{\prime}\left(c_{2 \alpha}^{N B}(e, \tau)\right)}{u^{\prime}\left(c_{2 \beta}^{N B}(e, \tau)\right)}<\frac{1-R q}{R-R q}
$$

Given that investors utility is constant relative risk aversion with parameter $\gamma>1$, the above holds if and only if the parameters of the model satisfy:

$$
\frac{R^{\frac{1-\gamma}{\gamma}}}{\pi+(1-\pi) R^{\frac{1-\gamma}{\gamma}}}<\left(\frac{1-R q}{R-R q}\right)^{\frac{1}{\gamma}}
$$

which is the same as condition (25).

\section{Proposition 3.}

Proof. We must show that $c_{1}^{B}(e, \tau)>c_{1}^{N B}(e, \tau)$. The proof is by contradiction. Suppose that

$$
c_{1}^{B}(e, \tau) \leq c_{1}^{N B}(e, \tau)
$$

then

$$
u^{\prime}\left(c_{1}^{B}(e, \tau)\right) \geq u^{\prime}\left(c_{1}^{N B}(e, \tau)\right)
$$

From Proposition $2, c_{1}^{B}(e, \tau)$ is characterized by

$$
u^{\prime}\left(c_{1}^{B}(e, \tau)\right)=(1-q) \mu_{\alpha}^{B}(e, \tau)
$$

whenever a bank best responds by qualifying for a bailout and by 


$$
u^{\prime}\left(c_{1}^{N B}(e, \tau)\right)=(1-q) \mu_{\alpha}^{N B}(e, \tau)+q \mu_{\beta}^{N B}(e, \tau)
$$

whenever a bank best responds by self-insuring. From (22) and (23) we obtain:

$$
(1-q) \mu_{\alpha}^{B}(e, \tau) \geq(1-q) \mu_{\alpha}^{N B}(e, \tau)+q \mu_{\beta}^{N B}(e, \tau)
$$

and since $\mu_{\beta}^{N B}(e, \tau)>0$, we must have:

$$
\mu_{\alpha}^{B}(e, \tau)>\mu_{\alpha}^{N B}(e, \tau)
$$

Combining the above expression with (11) yields:

$$
c_{2 \alpha}^{B}(e, \tau)<c_{2 \alpha}^{N B}(e, \tau)
$$

Working with the budget constraint in state $\alpha$ :

$$
\begin{gathered}
(1-\tau) e=\pi c_{1}^{B}(e, \tau)+(1-\pi) \frac{c_{2 \alpha}^{B}(e, \tau)}{R} \\
<\pi c_{1}^{N B}(e, \tau)+(1-\pi) \frac{c_{2 \alpha}^{N B}(e, \tau)}{R} \\
=(1-\tau) e
\end{gathered}
$$

i.e. $(1-\tau) e<(1-\tau) e$ which is a contradiction. Therefore the initial assumption $c_{1}^{B}(e, \tau) \leq$ $c_{1}^{N B}(e, \tau)$ cannot be true and we must have $c_{1}^{B}(e, \tau)>c_{1}^{N B}(e, \tau)$ as desired.

\section{Proposition 4.}

Proof. Follows from the discussion in the text.

\section{Proposition 5.}

Proof. Suppose that $X(\tau) \neq \emptyset$, let $x \in X(\tau)$, and consider a panic set of investor types which is given by $P(\tau)=\left[x, e_{H}\right]$. That is, investors with endowment $e_{L} \leq e<x$ follow the no panic strategy in (1) whereas investors with endowment $x \leq e \leq e_{H}$ follow the panic strategy in (2).

First, if type $e$ investors follow the no-panic strategy, then from (5) only impatient investors are among those to withdraw before the state is inferred by type $e$ banks, hence $\pi_{\alpha}(e)=\pi_{\beta}(e)=$ 0 . In addition, type $e$ banks do not experience a run and therefore do not receive a bailout. From (7), (8), (11) and (23) we obtain that the payment schedule in banks whose investors do not panic is not contingent on $s$ :

$$
\begin{gathered}
c_{1}^{N P}(e, \tau)=c_{1 \beta}^{N P}(e, \tau) \\
c_{2}^{N P}(e, \tau) \equiv c_{2 \beta}^{N P}(e, \tau)=c_{2 \alpha}^{N P}(e, \tau)
\end{gathered}
$$

where $c_{1}^{N P}(e, \tau)$ and $c_{2}^{N P}(e, \tau)$ will be the solution to:

$$
\pi c_{1}^{N P}(e, \tau)+(1-\pi) \frac{c_{2}^{N P}(e, \tau)}{R}=(1-\tau) e
$$




$$
u^{\prime}\left(c_{1}^{N P}(e, \tau)\right)=R u^{\prime}\left(c_{2}^{N P}(e, \tau)\right)
$$

Observe that these two equations are standard in a Diamond and Dybvig model. Moreover, since $R>1$ we have $c_{1}^{N P}(e, \tau)<c_{2}^{N P}(e, \tau)$ i.e. all types that follow the no-panic strategy will be best responding.

Second, consider type $x$ investors. Since $x \in X(\tau)$ we have from (28):

$$
D\left(x, \tau ;\left[x, e_{H}\right]\right)>0
$$

i.e. type $x$ banks best respond by qualifying for a bailout. In addition, from (27), there must exist $e^{N B}$ such that:

$$
D\left(e^{N B}, \tau ;\left[x, e_{H}\right]\right) \geq 0 \quad \text { with } \quad "=^{\prime \prime} \quad \text { if } e^{N B}<e_{H}
$$

Further, from (27) it follows that the above function is decreasing in $e$. Thus, we have $D\left(e^{N B}, \tau ;\left[x, e_{H}\right]\right)>0$ for $x \leq e<e^{N B}$ and $D\left(e^{N B}, \tau ;\left[x, e_{H}\right]\right)<0$ for $e^{N B}<e \leq e_{H}$. Therefore, banks servicing investors with $x \leq e<e^{N B}$ qualify for a bailout and set $c_{1}(e, \tau)$ as in (22). On the other hand, banks servicing investors with $e^{N B}<e \leq e_{H}$ prefer to self-insure and set $c_{1}(e, \tau)$ as in (23). Next, we must show that all investors with endowment in the interval $\left[x, e_{H}\right]$ are best responding with the panic strategy in (2). Since $x \in X(\tau)$ we obtain from (28):

$$
c_{1}^{B}(x, \tau) \geq c_{2 \beta}^{B}\left(\tau ;\left[x, e_{H}\right]\right)
$$

that is, type $x$ investors have an incentive to panic in state $\beta$. From (10), (11) and (22) we obtain that $c_{1}^{B}(e, \tau)$ is an increasing function of $e$ and hence, for each $e$ such that $x<e<e^{N B}$ :

$$
c_{1}^{B}(e, \tau)>c_{2 \beta}^{B}\left(\tau ;\left[x, e_{H}\right]\right)
$$

hence all investors with endowment in the interval $\left(x, e^{N B}\right)$ also have an incentive to panic in state $\beta$. In addition, (24) implies that:

$$
c_{1}^{B}(e, \tau)<c_{2 \alpha}^{B}(e, \tau)
$$

therefore all investors whose endowment belongs to the interval $e \in\left[x, e^{N B}\right)$ will be best responding with the panic strategy in (2). Finally, from (25) we obtain that the condition in (4) is satisfied in all banks choosing to self-insure and therefore investors whose endowment exceeds $e^{N B}$ will also be best responding with the panic strategy.

Propositions 6 and 7 use the following lemma.

Lemma 2. If $P(\tau) \subset P^{*}(\tau)$, then $b(e, \tau ; P(\tau)) \geq b\left(e, \tau ; P^{*}(\tau)\right)$ for $e \in P(\tau) \cap P^{*}(\tau)$

Proof. The proof is by contradiction: suppose this were not true. That is, there exist $\hat{e} \in P(\tau)$ such that: 


$$
b(\hat{e}, \tau, P(\tau))<b\left(\hat{e}, \tau, P^{*}(\tau)\right)
$$

From, (10), (11) and (22) it follows that $c_{1}^{B}(\hat{e}, \tau)$ - the payment to type $\hat{e}$ investor withdrawing before the state is inferred by the banks - is the same, when the panic set is either $P(\tau)$ or $P^{*}(\tau)$. Hence, we have:

$$
(1-\tau) e-\pi c_{1}^{B}(\hat{e}, \tau)+b(\hat{e}, \tau ; P(\tau))<(1-\tau) e-\pi c_{1}^{B}(\hat{e}, \tau)+b\left(\hat{e}, \tau ; P^{*}(\tau)\right)
$$

and from (14) and (15) we obtain:

$$
\psi_{\beta}^{B}(\tau, P(\tau))<\psi_{\beta}^{B}\left(\tau ; P^{*}(\tau)\right)
$$

from (10) and (11) it follows that:

$$
c_{1 \beta}^{B}(\tau, P(\tau))<c_{1 \beta}^{B}\left(\tau, P^{*}(\tau)\right)
$$

By applying (16), the existence of such a $\hat{e}$ would imply that for all $e \in P(\tau)$ :

$$
b(e, \tau ; P(\tau))<b\left(e, \tau ; P^{*}(\tau)\right)
$$

and this would imply that the aggregate bailout when the panic set of investor type is $P(\tau)$ is lower than to the aggregate bailout when the panic set of investor type is $P^{*}(\tau)$. Indeed, we have:

$$
\begin{aligned}
B(\tau ; P(\tau)) & =\int_{e \in P(\tau)} b(e, \tau, P(\tau)) d G \\
& <\int_{e \in P(\tau)} b\left(e, \tau, P^{*}(\tau)\right) d G \\
& \leq \int_{e \in P^{*}(\tau)} b^{*}\left(e, \tau, P^{*}(\tau)\right) d G \\
& =B^{*}\left(\tau ; P^{*}(\tau)\right)
\end{aligned}
$$

where the first inequality follows from $b(e, \tau, P(\tau))<b\left(e, \tau, P^{*}(\tau)\right)$ and the second inequality from our assumption that $P(\tau) \subset P^{*}(\tau)$. For fixed $\tau$, we have:

$$
\tau-B(\tau ; P(\tau))>\tau-B\left(\tau ; P^{*}(\tau)\right)
$$

and then (11) and (14) yields:

$$
c_{1 \beta}^{B}(\tau, P(\tau))>c_{1 \beta}^{B}\left(\tau, P^{*}(\tau)\right)
$$

which is a contradiction because (47) and (49) cannot both be true. Thus, our initial assumption, namely that there exist an investor type $\hat{e}$ such that $\hat{e} \in P(\tau)$ and whose bank receive larger per-capita bailout when the panic set is $P^{*}(\tau)$ cannot be true and we conclude that for all $e \in P(\tau)$ we must have:

$$
b(e, \tau ; P(\tau)) \geq b\left(e, \tau ; P^{*}(\tau)\right)
$$


as desired.

\section{Proposition 6.}

Proof. $D\left(y, \tau ;\left[y, e_{H}\right]\right) \leq 0$ implies that for $e>y$ we have $D\left(y, \tau ;\left[y, e_{H}\right]\right)<0$ and therefore banks will best respond by self-insuring. At the same time, the condition in (25) would imply that investors in banks that are not bailed out best respond with the panic strategy. Finally, given that all banks best respond by self-insuring, there will be no bailouts in equilibrium.

Next, I will derive some properties of $X(\tau)$ and $Y(\tau)$

(i) For each $\tau \in[0,1)$ we have $X(\tau) \cap Y(\tau)=\emptyset$.

To see this, suppose there exist $\tau^{*} \in[0,1)$ s.t. $X\left(\tau^{*}\right) \cap Y\left(\tau^{*}\right) \neq \emptyset$ and let $z \in X\left(\tau^{*}\right) \cap Y\left(\tau^{*}\right)$, then we must have $D\left(z, \tau^{*} ;\left[z, e_{H}\right]\right)>0$ and, at the same time, $D\left(z, \tau^{*} ;\left[z, e_{H}\right]\right) \leq 0$ - which is not possible and therefore $X(\tau) \cap Y(\tau)=\emptyset$.

(ii) If $x \in X(\tau)$ then each equilibrium panic set $P(\tau)$ such that $P(\tau) \subseteq\left[x, e_{H}\right]$ must be associated with bailouts in state $\beta$.

From (i) we have $x \in X(\tau) \Rightarrow x \notin Y(\tau)$ and therefore the subgame for $\tau$ and a panic set $\left[x, e_{H}\right]$ would involve bailouts when the state is $\beta$. Next, applying Lemma 2 for $e \in P(\tau) \subset$ $\left[x, e_{H}\right]$, we have $b\left(e, \tau ;\left[x, e_{H}\right]\right) \leq b(e, \tau ; P(\tau))$, which implies $c_{1 \beta}^{B}\left(\tau ;\left[x, e_{H}\right]\right) \leq c_{1 \beta}^{B}(\tau ; P(\tau))$ and therefore

$$
0<D\left(e, \tau ;\left[x, e_{H}\right]\right) \leq D(e, \tau ; P(\tau))
$$

That is, if type $e$ banks best respond by qualifying for a bailout when the panic set is $\left[x, e_{H}\right]$ they would also best respond by qualifying for a bailout when the panic set is $P(\tau) \subset\left[x, e_{H}\right]$.

(iii) If $X(\tau)=\emptyset$ and $Y(\tau)=\emptyset$ then a panic equilibrium does not exist for the given $\tau$.

Suppose there is $P(\tau) \neq \emptyset$ consistent with equilibrium and let

$$
z \equiv\left\{e \in P(\tau) \text { s.t } e \leq e^{\prime} \text { for each } e^{\prime} \in P(\tau)\right\}
$$

we must have $P(\tau) \subseteq\left[z, e_{H}\right]$. From (ii), if type $z$ banks qualify for a bailout when the panic set is $\left[z, e_{H}\right]$, they would also qualify for a bailout when the panic set is $P(\tau)$. In addition, from (ii) we have $c_{1 \beta}^{B}\left(\tau ;\left[z, e_{H}\right]\right) \leq c_{1 \beta}^{B}(\tau ; P(\tau))$. Finally, since $X(\tau)=\emptyset$, we must have $c_{1}^{B}(z, \tau)<$ $c_{2 \beta}^{B}\left(\tau ;\left[z, e_{H}\right]\right)$ and therefore $c_{1}^{B}(z, \tau)<c_{2 \beta}^{B}(\tau ; P(\tau))$, which implies that $P(\tau)$ cannot be an equilibrium panic set because type $z$ investors are not best responding with the panic strategy.

\section{Proposition 7.}

Proof. I will show that any panic set $P(\tau) \subseteq\left[e_{L}, e_{H}\right]$ such that $e \in P(\tau)$ and $e_{L} \leq e<e^{T}(\tau)$ will not be consistent with equilibrium for the given value of $\tau$. The proof is divided into two steps.

Step 1 Show that for any $e^{*}$ such that $e_{L} \leq e^{*}<e^{T}(\tau)$ the panic set $P(\tau)=\left[e^{*}, e_{H}\right]$ cannot be part of equilibrium. We must show that there exist $e \in\left[e^{*}, e_{H}\right]$ such that: 


$$
c_{1}^{B}(e, \tau)<c_{2 \beta}^{B}\left(\tau ;\left[e^{*}, e_{H}\right]\right)
$$

which would imply that type $e$ investors are not best responding with the panic strategy. The proof is by contradiction: suppose there exist $e_{1} \in\left[e_{L}, e^{T}(\tau)\right)$ such that the panic set $\left[e_{1}, e_{H}\right]$ is consistent with equilibrium in the subgame for $\tau$. We have must have:

$$
c_{1}^{B}\left(e_{1}, \tau\right) \geq c_{2 \beta}^{B}\left(\tau ;\left[e_{1}, e_{H}\right]\right)
$$

Next, we must have $e_{1}>e_{L}$. The reason is that by assumption

$$
c_{1}^{B}\left(e_{L}, \tau\right)<c_{2 \beta}^{B}\left(\tau ;\left[e_{L}, e_{H}\right]\right)
$$

which implies that $\left[e_{1}, e_{H}\right]$ is not an equilibrium panic set when $e_{1}=e_{L}$. Also, since $e_{1}<e^{T}(\tau)$ it follows that $e_{1}$ is not a threshold endowment type and therefore:

$$
c_{1}^{B}\left(e_{1}, \tau\right)>c_{2 \beta}^{B}\left(\tau ;\left[e_{1}, e_{H}\right]\right)
$$

Since $e_{1}>e_{L}$ we have $\left[e_{1}, e_{H}\right] \subset\left[e_{L}, e_{H}\right]$ and by lemma 2:

$$
c_{2 \beta}^{B}\left(\tau ;\left[e_{L}, e_{H}\right]\right) \leq c_{2 \beta}^{B}\left(\tau ;\left[e_{1}, e_{H}\right]\right)
$$

which implies:

$$
c_{1}^{B}\left(e_{L}, \tau\right)<c_{2 \beta}^{B}\left(\tau ;\left[e_{1}, e_{H}\right]\right)
$$

and we have

$$
c_{1}^{B}\left(e_{L}, \tau\right)<c_{2 \beta}^{B}\left(\tau ;\left[e_{1}, e_{H}\right]\right) \quad \text { and } \quad c_{1}^{B}\left(e_{1}, \tau\right)>c_{2 \beta}^{B}\left(\tau ;\left[e_{1}, e_{H}\right]\right)
$$

Next, since $c_{1}^{B}(e, \tau)$ is an increasing function of $e$ there must exist $e_{2}$ s.t. $e_{L}<e_{2}<e_{1}$ and

$$
c_{1}^{B}\left(e_{2}, \tau\right)=c_{2 \beta}^{B}\left(\tau ;\left[e_{1}, e_{H}\right]\right)
$$

and we have:

$$
c_{1}^{B}\left(e_{2}, \tau\right)=c_{2 \beta}^{B}\left(\tau ;\left[e_{1}, e_{H}\right]\right) \geq c_{2 \beta}^{B}\left(\tau ;\left[e_{2}, e_{H}\right]\right)
$$

where the last inequality follows from $e_{2}<e_{1}$ and lemma 2. Next, $e_{2}$ is not a threshold endowment since $e_{2}<e^{T}(\tau)$ and hence:

$$
c_{1}^{B}\left(e_{2}, \tau\right)>c_{2 \beta}^{B}\left(\tau ;\left[e_{2}, e_{H}\right]\right)
$$

By repeating the above procedure for $e_{2}$ we obtain that there must exist $e_{3}$ s.t. $e_{L}<e_{3}<e_{2}$ and

$$
c_{1}^{B}\left(e_{3}, \tau\right)>c_{2 \beta}^{B}\left(\tau ;\left[e_{3}, e_{H}\right]\right)
$$


Therefore we can construct a decreasing sequence, $\left\{e_{i}\right\}_{i=1}^{\infty}$, bounded from below by $e_{L}$ and hence convergent to $e_{L}$ :

$$
\lim _{i \rightarrow \infty} e_{i}=e_{L}
$$

where for each $i$ we have:

$$
\xi\left(e_{i}\right) \equiv c_{1}^{B}\left(e_{i}, \tau\right)-c_{2 \beta}^{B}\left(\tau ;\left[e_{i}, e_{H}\right]\right)>0
$$

Taking the limit of $\left\{\xi\left(e_{i}\right)\right\}_{i=1}^{\infty}$ to obtain:

$$
\lim _{i \rightarrow \infty} \xi\left(e_{i}\right) \rightarrow \xi\left(e_{L}\right)=c_{1}^{B}\left(e_{L}, \tau\right)-c_{2 \beta}^{B}\left(\tau ;\left[e_{L}, e_{H}\right]\right)<0
$$

Therefore there must exist $\hat{i}$ such that for $i>\hat{i}$ we have $\xi\left(e_{i}\right)<0$ - a contradiction since we must also have $\xi\left(e_{i}\right)>0$ for each $i$. As a result, we conclude that our initial assumption $c_{1}^{B}\left(e_{1}, \tau\right) \geq c_{2 \beta}^{B}\left(\tau ;\left[e_{1}, e_{H}\right]\right)$ cannot be true and we must have:

$$
c_{1}^{B}\left(e_{1}, \tau\right)<c_{2 \beta}^{B}\left(\tau ;\left[e_{1}, e_{H}\right]\right)
$$

That is, for each $e_{1}$ with $e_{1}<e^{F}(\tau)$, the panic set $\left[e_{1}, e_{H}\right]$ cannot be part of equilibrium.

Step 2 Consider $P(\tau) \subseteq\left[e_{L}, e_{H}\right]$ and define:

$$
e^{*} \equiv\{e \in P(\tau) \text { s.t.e } \leq z \text { for all } z \in P(\tau)\}
$$

If $e^{*}<e^{T}(\tau)$, by step 1 the panic set $\left[e^{*}, e_{H}\right]$ cannot be part of equilibrium and we must have $P(\tau) \subset\left[e^{*}, e_{H}\right]$. But, applying lemma 2, we also obtain that:

$$
c_{1}^{B}\left(e^{*}, \tau\right)<c_{2 \beta}^{B}\left(\tau ;\left[e^{*}, e_{H}\right]\right) \leq c_{2 \beta}^{B}(\tau ; P(\tau))
$$

hence $P(\tau)$ cannot be part of equilibrium whenever there is $e$ such that $e \in P(\tau)$ and $e<$ $e^{T}(\tau)$.

\section{Proposition 8.}

Proof. See the discussion in the text.

\section{Proposition 9.}

Proof. (i) We want to show that for each $\tau \in(0,1)$ there exist a wealth gap $\Delta^{*} \in\left[0, f^{-1}\right)$ such that for $\Delta \in\left(\Delta^{*}, f^{-1}\right)$ the equilibrium where the low-income investors follow the panic strategy does not exist. That is, we must show that when $\Delta>\Delta^{*}$ those with low-income will not be best responding with the panic strategy in (2):

$$
c_{1}\left(e_{L}(\Delta), \tau\right)<c_{2 \beta}\left(e_{L}(\Delta), \tau\right)
$$


For given values of $\tau$ and $\Delta$, let $b^{*}\left(e_{L}(\Delta), \tau\right)$ be defined as the solution to:

$$
c_{1}^{B}\left(e_{L}(\Delta), \tau\right)=\frac{R^{\frac{1}{\gamma}}\left((1-\tau) e_{L}(\Delta)-\pi c_{1}^{B}\left(e_{L}(\Delta), \tau\right)+b^{*}\left(e_{L}(\Delta), \tau\right)\right)}{\left.(1-\pi)\left(\pi+(1-\pi) R^{\frac{1-\gamma}{\gamma}}\right)\right)}
$$

From (10) - (11) and (22), the function $f_{L}(\Delta)$ :

$$
f_{L}(\Delta) \equiv(1-\tau) e_{L}(\Delta)-\pi c_{1}\left(e_{L}(\Delta), \tau\right)
$$

is decreasing in $\Delta$. In addition, $c_{1}^{B}\left(e_{L}(\Delta), \tau\right)$ is also decreasing in $\Delta$ and hence we have:

$$
c_{1}^{B}\left(e_{L}(\Delta), \tau\right)<c_{2 \beta}^{B}\left(e_{L}(\Delta), \tau\right) \Leftrightarrow b\left(e_{L}(\Delta), \tau\right)>b^{*}\left(e_{L}(\Delta), \tau\right)
$$

From, (13) - (16), and the fact that $f_{L}(\Delta)$ is decreasing in $\Delta$, we also obtain:

$$
\frac{\partial b\left(e_{L}(\Delta), \tau\right)}{\partial \Delta}>0
$$

The above implies that there exist $\tilde{\Delta} \in\left[0, f^{-1}\right)$ such that for $\Delta>\tilde{\Delta}$ banks servicing those with low-income best respond by qualifying for a bailout, i.e. $W\left(e_{L}(\Delta), \tau\right)>0$ for $\Delta>\tilde{\Delta}$. Finally, for $\Delta \rightarrow f^{-1}$ we have $f_{L}(\Delta) \rightarrow 0$ and therefore $b^{*}\left(e_{L}(\Delta), \tau\right) \rightarrow 0$. Hence, there must exist a level of inequality $\Delta^{* *} \in\left[0, f^{-1}\right)$ such that for $\Delta>\Delta^{*} \equiv \max \left\{\Delta^{* *}, \tilde{\Delta}\right\}$ we have $b^{*}\left(e_{L}(\Delta), \tau\right)<b\left(e_{L}(\Delta), \tau\right)$, which in turn implies that $c_{1}^{B}\left(e_{L}(\Delta), \tau\right)<c_{2 \beta}^{B}\left(e_{L}(\Delta), \tau\right)$. That is, when the wealth gap is sufficiently large, banks servicing investors with low-income would best respond by qualifying for a bailout and, at the same time, the anticipated bailout would prevent a panic for the low-income investors from taking place in equilibrium. As a result, an equilibrium run on the banks cannot involve those with low-income when $\Delta>\Delta^{*}$.

(ii) I will show that for each value of the tax rate $\tau$ in the interval $(0,1)$ we can find $\hat{f}>0$ and $\hat{\Delta} \in\left[0, \hat{f}^{-1}\right)$ such that for $f<\hat{f}$ and for $\Delta>\hat{\Delta}$ there exists an equilibrium where the highincome investors follow the panic strategy in (2). First, by an argument analogous to part (i), we can show that for each $\tau$, the bailout to banks providing intermediation to investors with high-income is strictly decreasing as a function of the wealth gap $\Delta$ :

$$
\frac{\partial b\left(e_{H}(\Delta), \tau\right)}{\partial \Delta}<0
$$

Second, let $e^{N B}(\tau)$ be such that $W\left(e^{N B}(\tau), \tau\right)<0$ for $e>e^{N B}(\tau)$. That is, when the tax rate is equal to $\tau$, those banks servicing investors whose endowment exceeds $e^{N B}(\tau)$ will choose to self-insure in case their investors follow the panic strategy. For each $e^{N B}(\tau)$ there must exist $\hat{f}>0$ such that for all $f<\hat{f}$ we have:

$$
e^{N B}(\tau)<1+\frac{(1-f)}{f}
$$


therefore for a wealth gap $\Delta$ in the range $\left(\hat{\Delta}, \frac{1}{f}\right)$, where $\hat{\Delta}$ is given by:

$$
\hat{\Delta}=\frac{e^{N B}(\tau)-1}{1-f}
$$

we would have:

$$
e_{H}(\Delta)=1+(1-f) \Delta>e^{N B}(\tau)
$$

and therefore

$$
W\left(e_{H}(\Delta), \tau\right)<0
$$

that is, for all $f<\hat{f}$ and for all $\Delta>\hat{\Delta}$ banks servicing those with high-income choose to selfinsure. Next, from (25) we obtain that high-income investors are best responding with the panic strategy when their banks are not bailed out. Therefore, when the level of inequality is sufficiently high, the equilibrium where the high-income investors run on the banks would exists.

\section{Proposition 10.}

Proof. Follows from the discussion in the text.

\section{Proposition 11.}

Proof. Suppose that $\Omega^{*}$ is a stable coalition structure and let $\left\{C_{k}^{*}(\tau)\right\}_{k=0}^{1}$ be the collection of payment schedules generated by $\Omega^{*}$. I show each $\Omega_{k}^{*} \in \Omega^{*}$ is not blocked only if for all $e \in \Omega_{k}^{*}$ we have $C_{k}^{*}(e, \tau)=C_{S}(e, \tau)$. That is, a stable coalition structure is payoff-equivalent to type specific coalition structure . There are two cases to consider. In case 1 , the coalition $\Omega_{k}^{*}$ is not bailed out, whereas in case 2 , coalition $\Omega_{k}^{*}$ is bailed out.

Case 1: No-bailout I derive the payment schedule for each $e \in \Omega_{k}^{*}$ under general set of weights and then show how to pick these weight in order to ensure that the proportional rule will be satisfied. Denote with $\omega_{k}(e)$ the weight on type $e$ investors in coalition $k$ and with $g_{k}(e)$ - the fraction of type $e$ investors in the coalition. In state $s$ the coalition distributes its remaining resources to maximize:

$$
V_{s}^{k}\left(\psi_{s}^{k}(\tau)\right) \equiv \int_{e_{L}}^{e_{H}} g_{k}(e) \omega_{k}(e)\left\{(1-\pi)\left[\pi_{s}(e) u\left(c_{1 s}^{k}(e, \tau)\right)+\left(1-\pi_{s}(e)\right) u\left(c_{2 s}^{k}(e, \tau)\right)\right]\right\} d e
$$

subject to the budget constraint in state $s$ :

$$
\int_{e_{L}}^{e_{H}} g_{k}(e)\left\{(1-\pi)\left[\pi_{s}(e) c_{1 s}^{k}(e, \tau)+\left(1-\pi_{s}(e)\right) \frac{c_{2 s}^{k}(e, \tau)}{R}\right]\right\} d e=\psi_{s}^{k}(\tau)
$$


and where $\psi_{s}^{k}(\tau)$ - the the remaining resources in state $s$ - are equal to:

$$
\psi_{S}^{k}(\tau)=\int_{e_{L}}^{e_{H}} g_{k}(e)\left[(1-\tau) e-\pi c_{1}^{k}(e, \tau)\right] d e
$$

The first order condition for type $e$ investors becomes:

$$
u^{\prime}\left(c_{1 s}^{k}(e, \tau)\right)=R u^{\prime}\left(c_{2 s}^{k}(e, \tau)\right)=\frac{\mu_{s}^{k}(\tau)}{\omega_{k}(e)}
$$

where $\mu_{s}^{k}(\tau)$ denotes the shadow on the budget constraint in state $s$. On the other hand, the payments during the first $\pi$ withdrawals will be set to maximize:

$$
\int_{e_{L}}^{e_{H}} g_{k}(e) \omega_{k}(e)\left\{\pi u\left(c_{1}^{k}(e, \tau)\right)\right\} d e+(1-q) V_{\alpha}^{k}\left(\psi_{\alpha}^{k}(\tau)\right)+q V_{\beta}^{k}\left(\psi_{\beta}^{k}(\tau)\right)
$$

and we obtain the following first order condition for type $e$ investors:

$$
u^{\prime}\left(c_{1}^{k}(e, \tau)\right)=(1-q) \frac{\mu_{\alpha}^{k}(\tau)}{\omega_{k}(e)}+q \frac{\mu_{\beta}^{k}(\tau)}{\omega_{k}(e)}
$$

Next, I use the functional form for $u$ (namely, constant relative risk aversion with $\gamma>1$ ) in order to derive an explicit solution for the payment schedule. In particular, the weights are normalized to satisfy:

$$
\int_{e_{L}}^{e_{H}} g_{k}(e)\left(w_{k}(e)\right)^{\frac{1}{\gamma}} d e=1
$$

and we obtain that the payment schedule for each investor type in the coalition is equal to:

$$
\begin{gathered}
c_{1}^{k}(e, \tau)=\left(w_{k}(e)\right)^{\frac{1}{\gamma}}(1-\tau) \hat{e}_{k} \frac{\lambda_{k}^{N B}}{1+\pi \lambda_{k}^{N B}} \\
c_{1 s}^{k}(e, \tau)=(w(e))^{\frac{1}{\gamma}}\left(\int_{e_{L}}^{e_{H}} g_{k}(e) \lambda_{s}(e) d e\right)\left(\frac{\psi_{s}^{k}(\tau)}{1-\pi}\right) \\
c_{2 s}^{k}(e, \tau)=R^{\frac{1}{\gamma}} c_{1 s}^{k}(e, \tau)
\end{gathered}
$$

where

$$
\begin{gathered}
\hat{e}_{k}=\int_{e_{L}}^{e_{H}} g_{k}(e) e d e \\
\lambda_{k}^{N B}=\frac{1}{1-\pi}\left\{(1-q)\left(\int_{e_{L}}^{e_{H}} g_{k}(e) \lambda_{\alpha}(e) d e\right)^{-\gamma}+q\left(\int_{e_{L}}^{e_{H}} g_{k}(e) \lambda_{\beta}(e) d e\right)^{-\gamma}\right\}^{-\frac{1}{\gamma}}
\end{gathered}
$$




$$
\begin{aligned}
& \lambda_{s}(e)=\frac{1}{\pi_{S}(e)+\left(1-\pi_{S}(e)\right) R^{1-\frac{1}{\gamma}}} \\
& \pi_{\alpha}(e)=0 \quad \text { for } \quad e \in\left[e_{L}, e_{H}\right] \\
& \pi_{\beta}(e)=\left\{\begin{array}{l}
0 \\
\pi
\end{array}\right\} \text { if }\left\{\begin{array}{l}
e \notin P(\tau) \\
e \in P(\tau)
\end{array}\right\}
\end{aligned}
$$

For $\left\{e_{1}, e_{2}\right\} \subseteq \Omega_{k}^{*}$, the proportional rule requires:

$$
\frac{c_{1}^{k}\left(e_{1}, \tau\right)}{c_{1}^{k}\left(e_{2}, \tau\right)}=\frac{c_{2 \alpha}^{k}\left(e_{1}, \tau\right)}{c_{2 \alpha}^{k}\left(e_{2}, \tau\right)}=\frac{c_{1 \beta}^{k}\left(e_{1}, \tau\right)}{c_{1 \beta}^{k}\left(e_{2}, \tau\right)}=\frac{c_{2 \beta}^{k}\left(e_{1}, \tau\right)}{c_{2 \beta}^{k}\left(e_{2}, \tau\right)}=\frac{e_{1}}{e_{2}}
$$

In order to satisfy this restriction, the coalition must assign weights to different type of investors according to:

$$
w_{k}(e)=\left(\frac{e}{\hat{e}_{k}}\right)^{\gamma}
$$

From (56) - (59) and (65) we obtain that the payment schedule for type $e$ investors in the coalition becomes:

$$
\begin{gathered}
c_{1}^{k}(e, \tau)=(1-\tau) e \frac{\lambda_{k}^{N B}}{1+\pi \lambda_{k}^{N B}} \\
c_{1 s}^{k}(e, \tau)=\left(\int_{e_{L}}^{e_{H}} g_{k}(e) \lambda_{s}(e) d e\right)\left(\frac{(1-\tau) e}{(1-\pi)\left(1+\pi \lambda_{k}^{N B}\right)}\right) \\
c_{2 s}^{k}(e, \tau)=R^{\frac{1}{\gamma}}\left(\int_{e_{L}}^{e_{H}} g_{k}(e) \lambda_{s}(e) d e\right)\left(\frac{(1-\tau) e}{(1-\pi)\left(1+\pi \lambda_{k}^{N B}\right)}\right)
\end{gathered}
$$

First, in the special case where all investors in the coalition have the same endowment $\{e\}=\Omega_{k}^{*}$, we have $w_{k}(e)=1$. The conditions characterizing the payment schedule in this case will be the same as (10), (11) and (23) and we have $C_{k}^{*}(e, \tau)=C_{S}(e, \tau)$. Second, if all investors in the coalition follow the same withdrawal strategy, (60) - (68) would imply that for each $e \in \Omega_{k}^{*}$ we have $C_{k}^{*}(e, \tau)=C_{S}(e, \tau)$. Third, if a fraction of the investors in $\Omega_{k}^{*}$ follow the panic strategy, then (60) - (68) imply that each investor type that follows the no-panic withdrawal strategy and belongs to $\Omega_{k}^{*}$ will be strictly better off by forming their own coalition since for $e \notin P(\tau)$ we have $C_{k}^{*}(e, \tau) \ll C_{S}(e, \tau)$ and therefore $W_{k}(e, \tau)<W_{S}(e, \tau)$. Thus, any coalition with $b_{k}(\tau)=0$ mixing investors that follow the panic withdrawal strategy with investors that follow the nopanic withdrawal strategy will be blocked and as a result cannot belong to a stable coalition structure. We conclude that for $e \in \Omega_{k}^{*}$ such that $b_{k}(\tau)=0$ we have $C_{k}^{*}(e, \tau)=C_{S}(e, \tau)$.

Case 2: Bailout When $b_{k}(\tau)>0$, then for $e \in \Omega_{k}^{*}$ the payment schedule for type $e$ investors 
in state $\beta$ - $\left(c_{1 \beta}^{k}(e, \tau), c_{2 \beta}^{k}(e, \tau)\right)$ - will be set by the government according to (40) - (42). We want to show that for each $e \in \Omega_{k}^{*}$, we have $C_{k}(e, \tau)=C_{S}(e, \tau)$, that is, the payment schedule for the investors in $\Omega_{k}^{*}$ is payoff-equivalent to a separate coalition for each investor type in $\Omega_{k}^{*}$. So, define $\hat{c}_{2 \alpha}(e, \tau)$ as:

$$
\hat{c}_{2 \alpha}(e, \tau) \equiv \frac{R\left((1-\tau) e-\pi c_{1}^{k}(e, \tau)\right)}{(1-\pi)}
$$

Note that if there exist $e \in \Omega_{k}^{*}$ such that

$$
c_{2 \alpha}^{k}(e, \tau)>\hat{c}_{2 \alpha}(e, \tau)
$$

there must also exist $e^{\prime} \in \Omega_{k}^{*}$ such that:

$$
c_{2 \alpha}^{k}\left(e^{\prime}, \tau\right)<\hat{c}_{2 \alpha}\left(e^{\prime}, \tau\right)
$$

otherwise, we have:

$$
\int_{e_{L}}^{e_{H}} g_{k}(e)\left[c_{2 \alpha}^{k}(e, \tau)-\frac{R\left[(1-\tau) e-\pi c_{1}^{k}(e, \tau)\right]}{(1-\pi)}\right] d e>0
$$

which would violate the budget constraint in state $\alpha$. At the same time, if there is $e^{\prime} \in \Omega_{k}^{*}$ such that (71) holds then $\Omega_{k}^{*}$ will be blocked. The reason is that type $e^{\prime}$ would strictly prefer to form their own coalition. To see this, note from (69) that $\left(c_{1}^{k}\left(e^{\prime}, \tau\right), \hat{c}_{2 \alpha}\left(e^{\prime}, \tau\right)\right)$ is feasible when type $e^{\prime}$ operate their own coalition. In addition, $c_{2 \alpha}^{k}\left(e^{\prime}, \tau\right)<\hat{c}_{2 \alpha}\left(e^{\prime}, \tau\right)$ combined with (40) and (41) yields:

$$
\left(c_{1 \beta}^{S}\left(e^{\prime}, \tau\right), c_{2 \beta}^{S}\left(e^{\prime}, \tau\right)\right) \geq\left(c_{1 \beta}^{k}\left(e^{\prime}, \tau\right), c_{2 \beta}^{k}\left(e^{\prime}, \tau\right)\right)
$$

Thus we have $\left(c_{1}^{k}\left(e^{\prime}, \tau\right), c_{1 \beta}^{S}\left(e^{\prime}, \tau\right), c_{2 \beta}^{S}\left(e^{\prime}, \tau\right)\right) \geq\left(c_{1}^{k}\left(e^{\prime}, \tau\right) c_{1 \beta}^{k}\left(e^{\prime}, \tau\right), c_{2 \beta}^{k}\left(e^{\prime}, \tau\right)\right)$ and $c_{2 \alpha}^{k}\left(e^{\prime}, \tau\right)<$ $\hat{c}_{2 \alpha}\left(e^{\prime}, \tau\right)$, which would imply that type $e^{\prime}$ are better off on their own since:

$$
\begin{gathered}
\pi u\left(c_{1}^{k}\left(e^{\prime}, \tau\right)\right)+(1-q)(1-\pi) u\left(\hat{c}_{2 \alpha}\left(e^{\prime}, \tau\right)\right)+q(1-\pi)\left(\pi_{\beta}(e) u\left(c_{1 \beta}^{S}\left(e^{\prime}, \tau\right)\right)+\left(1-\pi_{\beta}(e)\right) u\left(c_{2 \beta}^{S}\left(e^{\prime}, \tau\right)\right)\right) \\
>\pi u\left(c_{1}^{k}\left(e^{\prime}, \tau\right)\right)+(1-q)(1-\pi) u\left(c_{2 \alpha}^{k}\left(e^{\prime}, \tau\right)\right)+q(1-\pi)\left(\pi_{\beta}(e) u\left(c_{1 \beta}^{k}\left(e^{\prime}, \tau\right)\right)+\left(1-\pi_{\beta}(e)\right) u\left(c_{2 \beta}^{k}\left(e^{\prime}, \tau\right)\right)\right)
\end{gathered}
$$

Therefore, if $\Omega_{k}^{*}$ is not blocked, we must have for each $e \in \Omega_{k}^{*}$ :

$$
c_{2 \alpha}^{k}(e, \tau)=\frac{R\left((1-\tau) e-\pi c_{1}^{k}(e, \tau)\right)}{(1-\pi)}
$$

Note that for each $e \in \Omega_{k}^{*}$ a separate bank for type $e$ will be able to exactly replicate $C_{k}(e, \tau)$ by setting $\left(c_{1}^{k}(e, \tau), c_{2 \alpha}^{k}(e, \tau)\right)=\left(c_{1}^{S}(e, \tau), c_{2 \alpha}^{S}(e, \tau)\right)$. Indeed, $\left(c_{1}^{k}(e, \tau), c_{2 \alpha}^{k}(e, \tau)\right)$ must satisfy (72) and therefore is feasible when type $e$ operate on their own. In addition, from (40) and (41) we obtain that if 


$$
\left(c_{1}^{S}(e, \tau), c_{2 \alpha}^{S}(e, \tau)\right)=\left(c_{1}^{k}(e, \tau), c_{2 \alpha}^{k}(e, \tau)\right)
$$

we must also have:

$$
\left(c_{1 \beta}^{S}(e, \tau), c_{2 \beta}^{S}(e, \tau)\right)=\left(c_{1 \beta}^{k}(e, \tau), c_{2 \beta}^{k}(e, \tau)\right)
$$

But the optimal payment schedule for type $e$ investors among all those satisfying (72) will coincide with the optimal payment schedule when this type operate on their own, namely $C_{S}(e, \tau)$. Therefore if $\Omega_{k}^{*}$ is not blocked, we must have $C_{k}(e, \tau)=C_{S}(e, \tau)$ for each $e \in \Omega_{k}^{*}$ as desired.

\section{References}

- Acemoglu, D. (2011) Thoughts on inequality and the financial crisis. In Presentation held at the American Economic Association.

- Andolfatto, David, Ed Nosal, and Neil Wallace (2007) "The role of independence in the Green-Lin Diamond-Dybvig model," Journal of Economic Theory 137: 709-715.

- Bianchi, Javier (2013) “Efficient bailouts?” NBER Working Paper No. 18587, revised, January.

- Boyd, John H., Chun Chang, and Bruce D. Smith (2002) “Deposit insurance: A reconsideration,” Journal of Monetary Economics 49: 1235-1260.

- Chari, V.V. and Patrick J. Kehoe (2013) "Bailouts, time inconsistency and optimal regulation," NBER Working Paper No. 19192, June.

- Cooper, Russell and Hubert Kempf (2015) "Deposit insurance and orderly liquidation without commitment: Can we sleep well?" Econ Theory

- Cooper, Russell and Thomas W. Ross (1998) "Bank runs: liquidity costs and investment distortions," Journal of Monetary Economics 41: 27-38.

- Chang, Roberto \& Velasco, Andres, 2000. "Banks, debt maturity and financial crises," Journal of International Economics, Elsevier, Elsevier, vol. 51(1), pages 169-194, June.

- Diamond, Douglas W. and Phillip H. Dybvig (1983) “Bank runs, deposit insurance, and liquidity,” Journal of Political Economy 91: 401-419.

- EFTA Court (2013), "Judgement of the Court (on deposit-guarantee schemes, Obligation of result, Emanation of the State, Discrimination)"

- Ennis, Huberto M. and Todd Keister (2009a) "Bank runs and institutions: The perils of intervention," American Economic Review 99: 1588-1607.

- Ennis, Huberto M. and Todd Keister (2009b) "Run equilibria in the Green-Lin model of financial intermediation," Journal of Economic Theory 144: 1996-2020. 
- Ennis, Huberto M. and Todd Keister (2010) “Banking panics and policy responses," Journal of Monetary Economics 57: 404-419.

- Farhi, Emmanuel and Jean Tirole (2012) "Collective moral hazard, maturity mismatch and systemic bailouts," American Economic Review 102: 60-93.

- Fitoussi, J., Saraceno, R. (2010) Europe: How Deep Is a Crisis? Policy Responses and Structural Factors Behind Diverging Performances, Journal of Globalization and Development, vol.1, issue1, article 17

- Fitoussi, J., Saraceno, R. (2011) Inequality, the crisis and after, Rivista di Politica Economica, 100 (I-III), Gennaio-Marzo.

- Freeman, Scott (1988) "Banking as the provision of liquidity,” Journal of Business 61: 45-64.

- Green, Edward J. (2010) “Bailouts,” Federal Reserve Bank of Richmond Economic Quarterly 96:11-32.

- Green, Edward J. and Ping Lin (2000) "Diamond and Dybvig's classic theory of financial intermediation: What's missing?" Minneapolis Fed Quarterly Review 24 (Winter), 3-13.

- Green, Edward J. and Ping Lin (2003) "Implementing efficient allocations in a model of financial intermediation," Journal of Economic Theory 109: 1-23.

- Harsanyi, J., (1974). "An equilibrium-point interpretation of stable sets and a proposed alternative definition”, Management Science, 20, 1472-1495.

- Keister, Todd (2015) “Bailouts and financial fragility," Review of Economic Studies, forthcoming.

- Kumhof, M., Rancière, R. (2011). “Inequality, leverage and crises” IMF working Paper 10/268.

- Martin, Antoine (2006) "Liquidity provision vs. deposit insurance: Preventing bank panics without moral hazard," Economic Theory 28, 197-211.

- Nosal, Jaromir and Guillermo Ordoñez (2013) “Uncertainty as commitment," NBER Working Paper No. 18766.

- Peck, James and Karl Shell (2003) “Equilibrium bank runs," Journal of Political Economy 111: 103-123.

- Ray, D., Vohra, R., (2015). "Coalition formation," Handbook of Game Theory with Economic Applications, in: Handbook of Game Theory with Economic Applications, volume 4, chapter 5, pages 239-326 Elsevier.

- Ranciere, Romain and Aaron Tornell (2011) "Financial liberalization: Efficiency gains and black holes," mimeo., October.

- Rajan, R. G. (2010) Fault Lines, Princeton University Press, Princeton, New Jersey

- Rogoff, Kenneth "The Optimal degree of commitment to an intermediate monetary target," Quarterly Journal of Economics 100 (November 1985), 1169-1189.

- Stiglitz, J.E. (2012) The Price of Inequality: How Today's Divided Society Endangers Our Future. W. W. Princeton NJ: Norton \& Company.

- Stiglitz, J. (2009) "The global crisis, social protection and jobs," International Labour Review, Vol. 148, No. 1-2, pp.1-13 
- Sibert, Ann (2012) “Deposit insurance after Iceland and Cyprus,” VoxEU.org, 2 Apr 2012.

- Wallace, Neil (1988) "Another attempt to explain an illiquid banking system: the Diamond and Dybvig model with sequential service taken seriously," Minneapolis Fed Quarterly Review 12 (Fall): 3-16.

- Wallace, Neil (1990) “A banking model in which partial suspension is best," Minneapolis Fed Quarterly Review 14 (Fall): 11-23. 